\title{
Masked priming of number judgments depends on prime validity and task
}

\author{
GLEN E. BODNER and AUDNY T. DYPVIK \\ University of Calgary, Calgary, Alberta, Canada
}

\begin{abstract}
The influence of brief masked primes (42 or $50 \mathrm{msec}$ ) on number target judgments is shown to be highly sensitive to the list-wide validity of the primes for performing a particular target task. Odd/even judgments were facilitated on parity-valid trials (e.g., 1-7) relative to parity-invalid trials (e.g., 6-7), especially when .8 rather than .2 of the trials were parity valid. The opposite pattern was observed with magnitude judgments relative to 5: Responses were facilitated on magnitude- valid trials (e.g., $6-7$ ) relative to magnitude-invalid trials (e.g., 1-7), especially when .8 of the trials were magnitude valid. These results are consistent with Bodner and Masson's (2001) claim that a processing episode constructed during a masked prime event is more likely to be recruited when there is a high probability that it will facilitate responding to the target.
\end{abstract}

Research examining how brief masked primes influence target processing is undergoing an important shift. The original intent of making primes invisible to subjects, by combining visual masking and brief prime-target stimulus onset asynchronies (SOAs), was twofold. First, these "precautions" were thought to prevent subjects from using the primes in strategic, task-specific ways (e.g., A. J. Marcel, 1983; see also Neely, 1991). Second, masking was thought to prevent the formation of an episodic memory trace for the prime event, thus preventing memory processes from contributing to priming (e.g., Forster $\&$ Davis, 1984). Strategies and memories were considered nuisance factors whose elimination enabled researchers to use priming manipulations to make inferences about how words, numbers, and other types of conceptual information are processed (e.g., Forster, 1998).

Initial findings suggested that masking had achieved these goals (e.g., Forster, 1998; Forster \& Davis, 1984). For example, on each trial in a classic masked priming study, Forster and Davis presented a mask (e.g., \#\#\#\#) for $500 \mathrm{msec}$, followed by a lowercase prime (e.g., straw vs. money) for $60 \mathrm{msec}$, followed by an uppercase target (e.g., STRAW); subjects made a word/nonword lexical decision to the target. Lexical decisions to word targets were facilitated on repetition-prime trials relative to unrelated-prime trials, suggesting that masked word primes automatically activated their corresponding entries in a mental lexicon. Similarly, masked priming effects observed with con-

The Natural Sciences and Engineering Research Council of Canada supported this research through a discovery grant to G.E.B. We thank Devin Nobert and Tara Wigington for their assistance with this research, and Mark Brysbaert, Steve Lindsay, Mike Masson, Arika Miyake, and John Vokey for their helpful suggestions. Correspondence concerning this article should be addressed to G. E. Bodner, Department of Psychology, University of Calgary, 2500 University Drive NW, Calgary, AB, T2N 1N4 Canada (e-mail: bodner@ucalgary.ca). ceptually related prime-target pairs (e.g., doctor- NURSE, 5-7, appealing-GIFT) have often been attributed to a spreading activation mechanism whereby the prime activates its own representation, and this activation automatically spreads to activate conceptually related representations (e.g., Greenwald, Draine, \& Abrams, 1996; Klinger \& Greenwald, 1995; Koechlin, Naccache, Block, \& Dehaene, 1999; Reynvoet \& Brysbaert, 1999).

However, several recent studies have begun to seriously question whether strategic and memory-based influences of primes are eliminated through masking. Klinger, Burton, and Pitts (2000) found that masked priming in several binary-decision tasks depended on the prime and target sharing the same binary response rather than on whether or not the prime and target were conceptually related. For example, lexical decisions for word targets were facilitated by a word prime relative to a nonword prime, but in contrast to an automatic spreading activation view, it did not matter whether or not the word prime was conceptually related to its target. More strikingly, the effect of a set of masked primes on a set of targets depended on the task at hand. In Klinger et al.'s fourth experiment, each masked prime was exclusively affect valid (e.g., CANDY-PUPPY) or animacy valid (e.g., RATBUNNY). Klinger et al. found facilitation on affect-valid trials relative to animacy-valid trials in the affect task, but the reverse pattern in the animacy task, leading them to conclude that "the types of meaning that are unconsciously accessed are constrained by participants' goals and present task demands" (p. 452).

In the number domain, which is the focus of the present work, Greenwald, Abrams, Naccache, and Dehaene (2003, Experiment 2) found that the effect of masked two-digit primes on magnitude judgments (relative to 55) to twodigit targets depended on the informativeness of each digit position. In a practice block, some subjects were induced to attend to the first target digit by making the second tar- 
get digit nondiagnostic (i.e., it was always 5), whereas other subjects were induced to attend to the second target digit. The diagnostic digit controlled priming in a subsequent priming block. The effects of these withinexperiment associations were generally stronger than were pre-experimental (i.e., semantic memory) associations (see also Abrams \& Greenwald, 2000), leading Greenwald et al. (2003) to conclude that "the unconscious form of memory observed in these studies has the flexibility to adapt to recent experience" (p. 245).

Naccache, Blandin, and Dehaene (2002) reported that masked priming occurs only when attention is focused on the window of time when the target appears. Magnitude judgments (relative to 5) were facilitated on magnitudevalid trials (e.g., 6-9) relative to magnitude-invalid trials (e.g., 4-9), but this effect disappeared when target presentations were either temporally unpredictable, not cued, or invalidly cued. Naccache et al. concluded that masked priming effects are not due to automatic spreading activation, instead requiring attention that can be influenced by "another source of information such as instructions and task context" (p. 423).

Forster and Davis's (1984) claim that masking prevents subjects from constructing an episode for a prime event has also been challenged. For example, masked repetition priming effects have been observed for nonwords in the lexical decision task (e.g., Bodner \& Masson, 1997) and in the word-naming task (e.g., Bodner \& Masson, 2004; Masson \& Isaak, 1999), although nonwords do not have lexical entries. Masson and Bodner (2003) summarized additional evidence supporting the claim that despite being subjectively invisible, masked prime events are nonetheless encoded into a form of memory that can be recruited to facilitate target processing.

Results such as these suggest that masking does not prevent task- and context-specific use of primes. The very paradigm that was designed to eliminate strategic and memory-based processes is increasingly being used to study these processes. Indeed, the masked priming paradigm provides researchers with a pivotal tool for studying the influence of stimulus characteristics, subject variables, task goals, and contextual manipulations on unconscious cognitive processes (e.g., Greenwald et al., 2003). A. J. Marcel (1983), in an early study of masked priming, foreshadowed this recent shift in thinking:

Psychologists have not realized what they are doing. Indeed, whenever they suspect that their studies are "contaminated" by "higher level" processes (postcategorical representations, beliefs, strategies), all too often their first response is to try to prevent their presence or influence. In fact, these "problems" present the most truly psychological issues and those domains worthy of infinitely more study than they are at present given. (p. 233)

A recent masked priming phenomenon that we believe is worthy of more study, and a memory-recruitment framework for explaining it, are described next. The present experiments then examine this recent phenomenon in the domain of number processing, allowing us to evaluate the memory-recruitment account relative to several alternative accounts.

\section{Influences of Prime Validity on Masked Priming}

Valid primes contain information that is helpful for responding to the target, whereas invalid primes contain information that is irrelevant to, or that interferes with, target responses. A prime-validity effect refers to an increase in priming when the proportion of valid versus invalid prime trials in the stimulus list is higher in one condition relative to another. For example, semantic priming is typically greater when the proportion of related prime-target pairs is high; this form of prime-validity effect is termed a relatedness-proportion effect (see Neely, 1991, for a review). Relatedness-proportion effects were primarily investigated using plainly visible targets and SOAs above $240 \mathrm{msec}$ and were interpreted (for example) as evidence that subjects will consciously use the prime to try to predict what the target will be when prime validity is high (i.e., an "expectancy" strategy; see Neely, 1991).

Changes in priming can always be attributed to differential use of intentional strategies if subjects are aware of the contextual element that is being manipulated across conditions (e.g., prime validity, target types, target format). Manipulations of masked prime validity, in contrast, are unlikely to allow subjects to form conscious, strategic intentions to modulate their use of the primes. Contrary to popular intuition, then, are the results from several recent studies in which robust prime-validity effects have been obtained with brief masked primes.

In a series of lexical decision experiments, Bodner and Masson (2001) typically found larger masked repetition priming effects for words when .8 as opposed to .2 of the primes in the stimulus list were repetition (vs. unrelated) primes. Bodner and Masson (2004) found an analogous effect in the naming task, showing that prime-validity effects are not restricted to binary judgment tasks. In addition, subjects can become attuned to conceptually based validity; Bodner and Masson (2003) found larger masked semantic priming effects in the lexical decision task when .8 versus .2 of the primes were valid. Finally, in a similar paradigm, Jaskowski, Skalska, and Verleger (2003) found prime-validity effects with nonalphanumeric stimuli. Subjects decided whether the left or right target square had two segments removed from its vertical sides. Left/right judgments were facilitated when the "cut squares" in the masked prime displays were on the same side as in the target display, particularly when .8 rather than .2 of the trials were side valid. Precautions were taken in each of these studies to ensure that awareness of the masked primes was not driving the prime-validity effects.

These studies suggest that subjects can often effectively adapt to the present processing situation even when they are unaware of important aspects of this situation (i.e., of the masked primes and their validity). It should be pointed out that prime-validity effects are not observed with masked primes under all conditions (Bodner \& Masson, 2001; Perea \& Rosa, 2002), nor in all 
tasks. In the masked word identification task, neither the proportion of homophonic (Brysbaert, 2001) nor semantic (Pecher, Zeelenberg, \& Raaijmakers, 2002) prime-target pairs has been found to influence priming with Dutch stimuli. The conditions determining when and where masked prime-validity effects are obtained deserve further attention, but their occurrence in both binary and nonbinary judgment tasks, and with both word and nonalphanumeric stimuli, attests to their replicability. In conjunction with the aforementioned demonstrations of task-sensitive masked priming (e.g., Greenwald et al., 2003; Klinger et al., 2000; Naccache et al., 2002), the prospect of a domain-general yet context-sensitive priming mechanism seems inviting. In the next section, we describe one well-known potential mechanism-memory.

\section{A Memory-Recruitment Account}

The basic idea we wish to extend here is that a memorybased process contributes to priming - including masked priming - in many domains (e.g., Bodner \& Masson, 1997, 2001, 2003, 2004; Hughes \& Whittlesea, 2003; Masson \& Isaak, 1999; Whittlesea \& Jacoby, 1990). The rationale for this memory-recruitment account of priming is outlined in depth in Masson and Bodner (2003). In brief, borrowing from Kolers's procedural framework (Kolers, 1973, 1975, 1976; Kolers \& Roediger, 1984), the processing operations applied to the prime are said to form a new memory representation that serves as an instance of episodic learning or skill acquisition of which the subject is unaware (e.g., Logan, 1988, 1990). Processing operations can include whatever work the cognitive system does with the prime in an effort to identify and interpret it (e.g., perceptual, orthographic, phonological, semantic). Transfer of this learning experience to the processing of a subsequent target depends on the compatibility of the processing operations performed on the prime and those needed to successfully process and respond to the target in the task at hand (i.e., transferappropriate processing; Morris, Bransford, \& Franks, 1977). This proposal also has an affinity with Jacoby's (1983; Jacoby \& Dallas, 1981) proposal that memory and perception are both determined by the ability of a target to unconsciously cue memories for similar prior episodes.

Whittlesea and Jacoby (1990) provided an important demonstration of a retrospective influence on priming. On repetition trials, a target (e.g., GREEN) was immediately preceded by two items, a 60 -msec prime (e.g., GREEN), and a 150-msec interpolated word (e.g., pLant or PLANT). Relative to various within-subjects control conditions, Whittlesea and Jacoby found that repetition priming of naming responses to targets was greater when the interpolated word was degraded via case alternation than when it was not degraded. Whittlesea and Jacoby put forward a retrieval view of priming to explain this result, arguing that the cognitive system was more likely to recruit the episode constructed for the prime to help in processing the interpolated word when that processing was made more challenging through degradation. The recruited prime episode was then more available to facilitate the identification of the subsequent target, resulting in a larger repetition priming effect. This result is inconsistent with a prospective spreading activation mechanism because the spread of activation from a prime cannot be made conditional on whether the subsequent interpolated word will be degraded.

To explain task- and prime-validity dependent priming, the memory-recruitment account appeals to the well-established finding that memory is influenced by contextual factors, such as the task instructions (e.g., Craik \& Tulving, 1975) and the proportion of studied versus new items presented at test (e.g., Allen \& Jacoby, 1990; Jacoby, 1983). For example, Allen and Jacoby found that subjects were better able to identify target words in a masked word identification task when .9 rather than .2 of them had been presented in an earlier task. This proportion overlap effect was attributed to increased recruitment of prior processing episodes when the study and test list contexts were made more similar.

Bodner and Masson (2001) applied this account to the masked priming paradigm to help explain prime-validity effects. When prime validity is high, the probability of a match between a prime and a target on any given trial is higher, which should promote a general increase in the recruitment of the prime resource, leading to an increase in priming. Other episodes can also be recruited from memory, but the prime resource is likely to be particularly available because it was encoded milliseconds earlier in the same experimental context. Moreover, the nature of the test task likely defines which properties of primes will be encoded and evaluated for their usefulness (e.g., Greenwald et al., 2003; Hughes \& Whittlesea, 2003; Klinger et al., 2000).

\section{Validity and Task-Dependent Priming With Number Stimuli}

The goal of the present experiments was to examine whether prime-validity effects with masked primes also occur with number stimuli, as expected if these effects reflect a domain-general mechanism such as memory recruitment. Specifically, we examined whether masked priming of number judgments can be influenced by the list-wide validity of the primes for making either odd/even parity judgments (Experiments 1-3) or less-than/morethan magnitude judgments (Experiment 3). The masked priming paradigm and these two tasks have been used extensively by researchers interested in number processing and representation (e.g., Dehaene et al., 1998; Greenwald et al., 2003; Koechlin et al., 1999; Naccache et al., 2002; Naccache \& Dehaene, 2001; Reynvoet \& Brysbaert, 1999; Reynvoet, Caessens, \& Brysbaert, 2002), so they provided a good arena for testing the generality of primevalidity effects.

Two types of priming have been investigated with number stimuli. Distance priming refers to an increase in response facilitation with a decrease in the numerical 
distance between the prime and target, and was described by den Heyer and Briand (1986) as follows:

It was assumed that single digit numbers are represented in semantic memory on some ordered continuum. Thus, five and six are more closely situated in semantic space than, say, five and seven. It follows that if activation in response to the presentation of the prime five dissipates with distance, then six should receive more activation than seven. This in turn should reflect itself in latency measures where the distance between the prime and target is varied. (p. 331)

den Heyer and Briand observed this pattern in letter/ number and lexical decision tasks with plainly visible primes. Distance effects also occur with masked primes in both the magnitude task (e.g., Dehaene et al., 1998; Koechlin et al., 1999; Naccache et al., 2002; Naccache \& Dehaene, 2001) and the parity task (e.g., Reynvoet \& Brysbaert, 1999; Reynvoet et al., 2002). Distance priming has been attributed to the prime activating an abstract magnitude representation (e.g., Koechlin et al., 1999) or an abstract ordinal number line representation (e.g., den Heyer \& Briand, 1986; Reynvoet \& Brysbaert, 1999; Reynvoet et al., 2002).

The second type of priming effect, response priming, can only occur in binary judgment tasks where some of the primes bias an incorrect response. Response priming reflects a benefit when the prime and target bias the same response relative to when they bias different responses (e.g., Neumann \& Klotz, 1994). For example, Koechlin et al. (1999) found that magnitude judgments were faster when the masked prime and the target were both less (e.g., 1-4) or both greater (e.g., 6-9) than the comparison standard of 5 , relative to when the primes were magnitude invalid (e.g., 1-6 or 6-4). In a parity task with masked primes, Reynvoet et al. (2002) reported that parity-valid primes further from their target (e.g., 1-3) facilitated responses more than parity-invalid primes closer to their target (e.g., 2-3). The latter result shows that response priming can be a more powerful determinant of priming than the semantic (i.e., numerical) similarity between the prime and target, as Klinger et al. (2000) reported for word stimuli. Response priming has most often been attributed to the need for extra time to overcome the cuing of the incorrect motor response on invalid trials (e.g., Dehaene et al., 1998; Koechlin et al., 1999; Naccache \& Dehaene, 2001; Neumann \& Klotz, 1994; Reynvoet et al., 2002). Using functional magnetic resonance imaging and event-related potential measures, Dehaene et al. (1998) showed that activation of the motor cortex during target processing was influenced by whether the masked prime had been congruent or incongruent with the target response.

Experiments 1 and 2 were designed to answer three questions. First, we wanted to verify Reynvoet et al.'s (2002) finding that (for example) 1 indeed primes 3 better than 2 primes 3 in a parity-judgment task. Note that the opposite pattern should be observed if masked priming of number judgments reflects only spreading activa- tion along an abstract number line (e.g., Brysbaert, 1995; den Heyer \& Briand, 1986; T. Marcel \& Forrin, 1974) or overlap in the activation of abstract magnitude representations (e.g., Koechlin et al., 1999). By using parity-valid primes two numbers away from their targets and parityinvalid primes one number away from their targets, the contributions of response priming (i.e., parity match) and distance priming (i.e., the numerical distance between prime and target) were pitted against each other. The memory-recruitment account predicts that subjects in a parity task should tune into the validity of the masked primes with respect to the dimension of parity match, resulting in a parity-valid priming advantage despite the consistent disadvantage in prime-target distance on these trials.

Second, the memory-recruitment account predicts that parity-valid priming should increase when .8 rather than .2 of trials are parity valid; prime validity was always .5 in Reynvoet et al. (2002). The demonstration of a primevalidity effect in a new stimulus domain would support the claim that the effect is produced by a domain-general mechanism such as memory recruitment. In contrast, prime-validity effects would not be expected if masked priming is due only to the context-independent activation of number or motor-response representations.

Third, following Koechlin et al. (1999), we manipulated whether stimuli were number words (Experiment 1) or Arabic digits (Experiment 2) to ensure that our findings were not specific to a particular notation format (and/or corresponding mental number code).

\section{EXPERIMENT 1 \\ Parity Judgments With Number Word Stimuli}

In Experiment 1, each parity-valid prime was response valid and two numbers away from its target (e.g., one-THREE, six-FOUR), whereas each parity-invalid prime was response invalid but only one number away from its target (e.g., four-THREE, three-FOUR). If the prime's parity has a greater influence on priming than its numerical distance from the target, parity judgments should be facilitated on parity-valid trials compared with parity-invalid trials. We also manipulated whether .2 or .8 of the prime-target pairs were parity valid. If the listwide validity of the primes influences priming, the .8valid group should show a larger parity-valid priming effect than the .2-valid group. For reasons described below, .6 of the valid trials in the .8-valid group were repetitionprime trials (e.g., three-THREE, four-FOUR).

\section{Method}

Subjects. Unique sets of undergraduate students from the University of Calgary participated in these experiments for course credit. The subjects were always randomly assigned to a prime-validity group. In Experiment 1, there were 20 subjects in the .2-valid group and 20 in the .8 -valid group.

Design. The subjects received a total of 360 trials, 180 with an even target and 180 with an odd target. Targets were number words three through eight, and primes were number words one through 
Table 1

Experiments 1 and 2: Prime-Target Pairs

\begin{tabular}{ccccccc}
\hline \multicolumn{3}{c}{ 180 Odd-Target Trials } & & \multicolumn{3}{c}{ 180 Even-Target Trials } \\
\cline { 1 - 3 } \cline { 5 - 7 } $\begin{array}{c}\text { Repetition } \\
\text { Trials }\end{array}$ & $\begin{array}{c}\text { Parity-Valid } \\
\text { Trials }\end{array}$ & $\begin{array}{c}\text { Parity-Invalid } \\
\text { Trials }\end{array}$ & & $\begin{array}{c}\text { Repetition } \\
\text { Trials }\end{array}$ & $\begin{array}{c}\text { Parity-Valid } \\
\text { Trials }\end{array}$ & $\begin{array}{c}\text { Parity-Invalid } \\
\text { Trials }\end{array}$ \\
\hline $3-3$ & $1-3,5-3$ & $2-3,4-3$ & & $4-4$ & $2-4,6-4$ & $3-4,5-4$ \\
$5-5$ & $3-5,7-5$ & $4-5,6-5$ & & $6-6$ & $4-6,8-6$ & $5-6,7-6$ \\
$7-7$ & $5-7,9-7$ & $6-7,8-7$ & & $8-8$ & $6-8,10-8$ & $7-8,9-8$ \\
\hline
\end{tabular}

Note-The 2 -valid groups in Experiments 1 and 2 received each of the 12 parity-valid prime-target pairs 6 times ( 72 of 360 trials $=.2$ ) and each of the 12 parity-invalid prime-target pairs 24 times ( 288 of 360 trials $=.8$ ). In Experiment 1 , the .8 -valid group received each of the 6 repetition trials 36 times $(216$ of $360=.6)$, each of the 12 valid prime-target pairs 6 times ( 72 of 360 trials $=.2$ ), and each of the 12 invalid prime-target pairs 6 times ( 72 of 360 trials $=.2$ ). In Experiment 2, the .8 -valid group received each of the 12 valid prime-target pairs 24 times ( 288 of 360 trials $=.8$ ) and each of the 12 invalid prime-target pairs 6 times ( 72 of 360 trials $=.2$ ). Note that there were no repetition prime trials in Experiment 2 and that stimuli were presented as number words in Experiment 1 and as digits in Experiment 2.

ten. The prime was two numbers less than the target on half of the nonrepetition parity-valid trials (e.g., one-THREE, two-FOUR) and two numbers greater on the other half (e.g., five-THREE, six-FOUR). The prime was one number less than the target on half of the parityinvalid trials (e.g., two-THREE, three-FOUR), and one number greater on the other half (e.g., four-THREE, five-FOUR). Table 1 lists the prime-target combinations used.

To help homogenize the level of prime validity across trials, trials were divided into six blocks of 60 trials with 30 trials of each target parity per block. In the 8 -valid group, repetition primes were presented on .6 of the valid trials, resulting in 18 repetition-prime trials (.6), 6 nonrepetition parity-valid trials (.2), and 6 parity-invalid trials $(.2)$ per target type per block. In the .2 -valid group, there were 6 nonrepetition parity-valid trials (.2) and 24 parity-invalid trials (.8) per target type per block. Hereafter, we use the terms repetition prime and parity-valid prime to refer to repetition parity-valid primes and nonrepetition parity-valid primes, respectively. The order of trials within each block was randomized for each subject.

Procedure. The subjects were tested individually in a room equipped with a Macintosh G4 computer connected to an Apple Studio 17-in. CRT monitor and a custom-built response box. Stimuli were presented in black 14-point Monaco font at $832 \times 624$ pixel resolution against a white background. The subject was positioned approximately $45 \mathrm{~cm}$ from the monitor. Displays were synchronized with the refresh cycle of the monitor. The subjects were told that "several briefly displayed items (e.g., a row of Xs)" would appear before the target appeared, but they were not specifically informed of the presence of the primes.

Each trial began with a row of seven uppercase Xs presented in the center of the screen for $500 \mathrm{msec}$. This mask was immediately followed by a lowercase number word prime that appeared in the same location. The prime remained on the screen for $50 \mathrm{msec}(6$ cycles at $120 \mathrm{~Hz}$ ) and was then replaced with an uppercase number word target in the same location, flanked with as many ampersands on either side as was required to make all targets seven characters long (after Bodner \& Masson, 2003). Primes and targets were often of different lengths, so this arrangement ensured complete masking of the prime by the target. The target, which served to postmask the prime, remained in view until a parity judgment was made by pressing one of two keys on the response box. The subjects were instructed to press the key labeled "even" with the right index finger if the target was an even number, and to press the key labeled "odd" with the left index finger if the target was an odd number. The subjects were instructed to respond as quickly and as accurately as possible. If an incorrect response was made, a tone sounded and INCORRECT RESPONSE was displayed for $1 \mathrm{sec}$; if the response took more than $1,500 \mathrm{msec}$, a tone sounded and TOO SLOW was displayed for $1 \mathrm{sec}$. A 1-sec intertrial interval occurred following a correct response or any corrective feedback. A self-paced rest break followed each block of 60 trials.

After the experiment, which took 10-15 min, the subjects were asked what they had seen on each trial, just before the target was presented. If they only reported seeing the mask, they were further asked if they had noticed anything else following the mask but before the target. The experimenter classified each subject into one of two categories: those who reported seeing only the mask and those who reported at least minimal awareness of a stimulus other than the mask.

\section{Results}

Reported prime awareness. Thirty percent of the .8valid group and $45 \%$ of the .2 -valid group reported being aware that a stimulus other than a row of Xs was presented before the target; these subjects were classified as prime aware. Separate analyses were conducted on the data from all subjects (the full data set) and on the data excluding prime-aware subjects (the unaware data set). Prime awareness had a negligible influence on the effects we report in our experiments, despite a substantial loss of power in the unaware data set (as in Bodner \& Masson, 2003, 2004). For brevity, only the results and followup tests from the full data set are discussed below. The relation between priming and awareness is more closely examined in Experiment 4.

Reaction times. To be consistent with earlier investigations (Bodner \& Masson, 2001, 2003, 2004), the following conventions were used throughout. The significance level was set at .05 . Trials with reaction times below $300 \mathrm{msec}$ or above $3 \mathrm{sec}$ were excluded from analysis (less than $0.5 \%$ of the trials in each experiment, as per Ulrich \& Miller, 1994). Separate analyses of variance (ANOVAs) were performed on mean reaction times and percent error rates, using subjects as the random factor. The means and their confidence intervals, based on the full data sets, are displayed graphically (see Figure 1 for Experiment 1; Loftus \& Masson, 1994; Masson \& Loftus, 2003). The left panels of each figure show the mean reaction time 


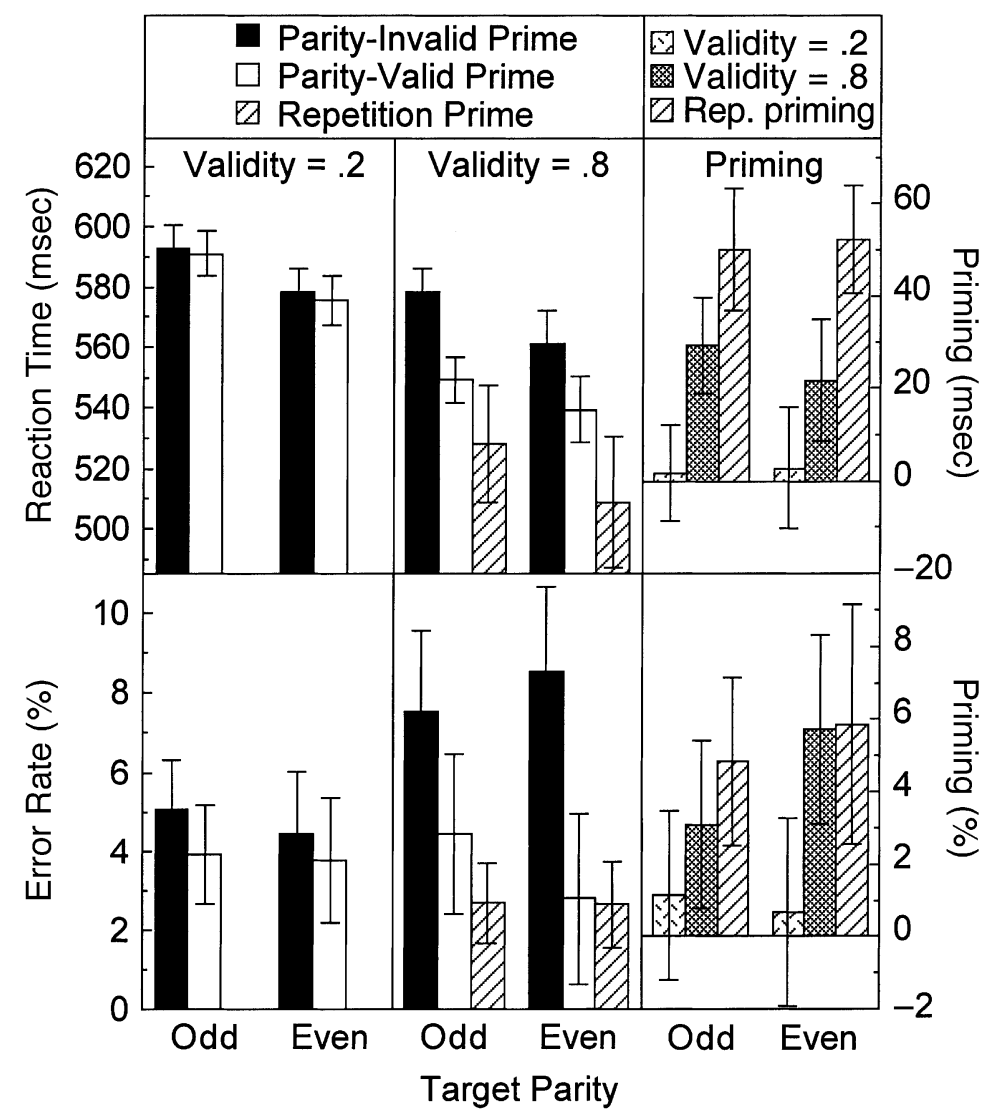

Figure 1. Experiment 1: Mean reaction time, error rate, and priming effect for odd and even targets as functions of prime type and prime validity. Error bars for reaction times and error rates (left panels) are $95 \%$ within-subjects confidence intervals, computed separately for each pair of valid and invalid means, and are appropriate for evaluating whether priming occurred (see Loftus \& Masson, 1994; Masson \& Loftus, 2003). Error bars for priming effects (right panels) are $95 \%$ between-subjects confidence intervals, computed for each target parity, and are appropriate for evaluating whether a prime-validity effect occurred. Separate $95 \%$ confidence intervals are plotted for each repetition condition mean.

(top) and percent error rate (bottom) for each prime and target combination as a function of prime validity. The right panels plot the difference between parity-valid and parity-invalid trials for each prime-validity group (i.e., priming), as well as the repetition-priming effect (the difference between parity-invalid and repetition-prime means) for the .8-valid group.

In Experiment 1, the mean reaction times and error rates (excluding repetition-prime trials) were analyzed using ANOVAs in which priming (parity-valid vs. parityinvalid) and target parity (even vs. odd) were withinsubjects factors and prime validity (.2 vs. .8) was a between-subjects factor. Appendix A lists the results of these ANOVAs. We discuss only the two most relevant results here: Whether priming occurred and whether it interacted with prime validity. The prime-validity effect did not interact with target type in these experiments (i.e., no three-way interactions were found). ${ }^{1}$ Priming within each prime-validity group was tested for significance using a one-way ANOVA.

As expected, parity judgments were faster on parityvalid than on parity-invalid trials, and this parity-valid advantage was greater when .8 trials were parity valid rather than .2 trials. The 25 -msec parity-valid effect in the .8 -valid group was significant $[F(1,19)=27.18$, $\left.M S_{\mathrm{e}}=238\right]$, whereas the 2-msec effect in the .2-valid group was not $(F<1)$. The .8 -valid group was also $39 \mathrm{msec}$ faster than the .2-valid group on parity-valid trials $\left[F(1,38)=7.34, M S_{\mathrm{e}}=2,075\right]$. Separate tests showed that within the .8 -valid group, repetition-prime trials were $51 \mathrm{msec}$ faster than parity-invalid trials $[F(1,19)=$ $\left.107.38, M S_{\mathrm{e}}=486\right]$ and were $25 \mathrm{msec}$ faster than parityvalid trials $\left[F(1,19)=34.18, M S_{\mathrm{e}}=193\right]$.

Error rates. As seen in Figure 1, the pattern in the error rates reinforces the pattern in the reaction times (i.e., no speed-accuracy tradeoffs occurred). The .8- 
valid group showed a larger parity-valid priming effect [3.6\% vs. $8.0 \%$, which a one-way ANOVA showed to be reliable; $\left.F(1,19)=14.66, M S_{\mathrm{e}}=13.22\right]$ than the .2 -valid group $[3.8 \%$ vs. $4.7 \%$, which were not different; $F(1,19)=$ $\left.2.23, M S_{\mathrm{e}}=3.74, p=.15\right]$. The .8 - and .2 -valid groups made a similar rate of errors on parity-valid trials $(F<1)$. In the .8 -valid group, repetition primes produced fewer errors than parity-invalid primes $[F(1,19)=22.41$, $\left.M S_{\mathrm{e}}=25.6\right]$, and the error rate on repetition and parityvalid trials did not differ $(F<1)$.

\section{Discussion}

Parity-valid primes two numbers away from their targets facilitated parity judgments more than did parityinvalid primes one number away from their targets. Thus, matching parity facilitated parity judgments more than did similarity in magnitude, as Reynvoet et al. (2002) reported. The key novel finding in Experiment 1 was that parity-valid priming was strongly governed by the listwide validity of the masked primes. Parity-valid priming was far greater (and was typically only reliable) when .8 rather than .2 of the trials were parity valid. Sensitivity to prime validity was observed even when primeaware subjects were excluded, suggesting that awareness of the primes is not required for the cognitive system to become tuned to prime validity (see Higham \& Brooks, 1997, for a similar result). Experiment 1 represents the first evidence that masked priming with numbers can be influenced by prime validity, a variable that has also been shown to affect masked priming with word stimuli (Bodner \& Masson, 2001, 2003, 2004) and nonalphanumeric stimuli (Jaskowski et al., 2003). This result bolsters the claim that a domain-general and context-sensitive mechanism contributes to masked priming.

Two other results from Experiment 1 provide clues as to the nature of this mechanism. First, responses on parityvalid trials were faster when prime validity was .8 rather than .2, although both groups were exposed to each parityvalid prime-target pair equally often. This finding suggests that the number of opportunities to learn specific prime-target associations (e.g., Damian, 2001) is not the basis of the greater facilitation in the .8-valid group. Second, responses were faster on repetition-prime trials than on parity-valid trials in the .8-valid group, although primes in both cases were congruent with the correct target response; Naccache and Dehaene (2001) reported a similar result in a magnitude task. Masked priming of parity and magnitude judgments is therefore influenced by factors in addition to whether the prime biases the correct target response (Greenwald et al., 2003; Naccache \& Dehaene, 2001; Reynvoet \& Brysbaert, 1999; Reynvoet et al., 2002).

The results of Experiment 1 are inconsistent with a purely activation-based account of number priming in which the presentation of a number prime activates the prime's representation (e.g., Dehaene et al., 1998; Koechlin et al., 1999) and causes it to automatically spread along an abstract number line to activate nearby number representations (e.g., Brysbaert, 1995; den Heyer \& Briand, 1986; T. Marcel \& Forrin, 1974). Greater priming by primes that are further from their targets cannot be due to automatic spreading activation. Furthermore, prime validity should not have affected automatic spreading activation (e.g., Neely, 1991).

We suggest that priming and prime-validity effects with masked primes fit well with a memory-recruitment account of priming (e.g., Masson \& Bodner, 2003). The nature of the target task likely influences the type of processing operations applied to the prime (e.g., Dehaene et al., 1998; Greenwald et al., 2003; Klinger et al., 2000; Naccache et al., 2002), so that subjects in Experiment 1 would likely have encoded information about the primes' parity. Priming depends on the compatibility of the processing applied to the prime and target events (e.g., Hughes \& Whittlesea, 2003), hence recruitment of prime episodes should facilitate parity judgments on parityvalid trials. Moreover, recruitment of the prime resource, like recruitment of any other memory, should be fostered by contextual overlap. Prime recruitment and priming should therefore increase as list-wide prime validity (i.e., prime-target overlap) increases (e.g., Allen \& Jacoby, 1990). The memory-recruitment account is thus compatible with prime-validity effects obtained with numbers, words, and nonalphanumeric stimuli.

\section{EXPERIMENT 2 Parity Judgments With Digit Stimuli}

To test the generality of prime-validity effects on masked priming of number judgments, Arabic digit stimuli were used in Experiment 2. The SOA was reduced to $42 \mathrm{msec}$ because pilot testing suggested that digits are more difficult to mask than number words. Also, repetition-prime trials in the .8-valid group were replaced with parity-valid trials to verify that primevalidity effects with number stimuli do not depend on the presence of repetition-prime trials.

\section{Method}

Subjects, Design, and Procedure. There were 20 subjects in the .2-valid group and 20 in the .8-valid group. Primes and targets were presented as digits. Repetition-prime trials in the .8-valid group were replaced by parity-valid trials (see Note, Table 1). A 42-msec SOA ( 5 cycles at $120 \mathrm{~Hz}$ ) was used to keep awareness of the primes to the same level as in Experiment 1. The premask was XXX, and a single ampersand flanked each target (e.g., \&9\&) to help postmask the prime. Otherwise, the design and procedure were the same as in Experiment 1.

\section{Results}

Figure 2 displays the means and confidence intervals. The ANOVAs were identical to those used in Experiment 1 (see Appendix A).

Reported prime awareness. With digits and a 42$\mathrm{msec} \mathrm{SOA}$, the percentage of subjects who reported being 


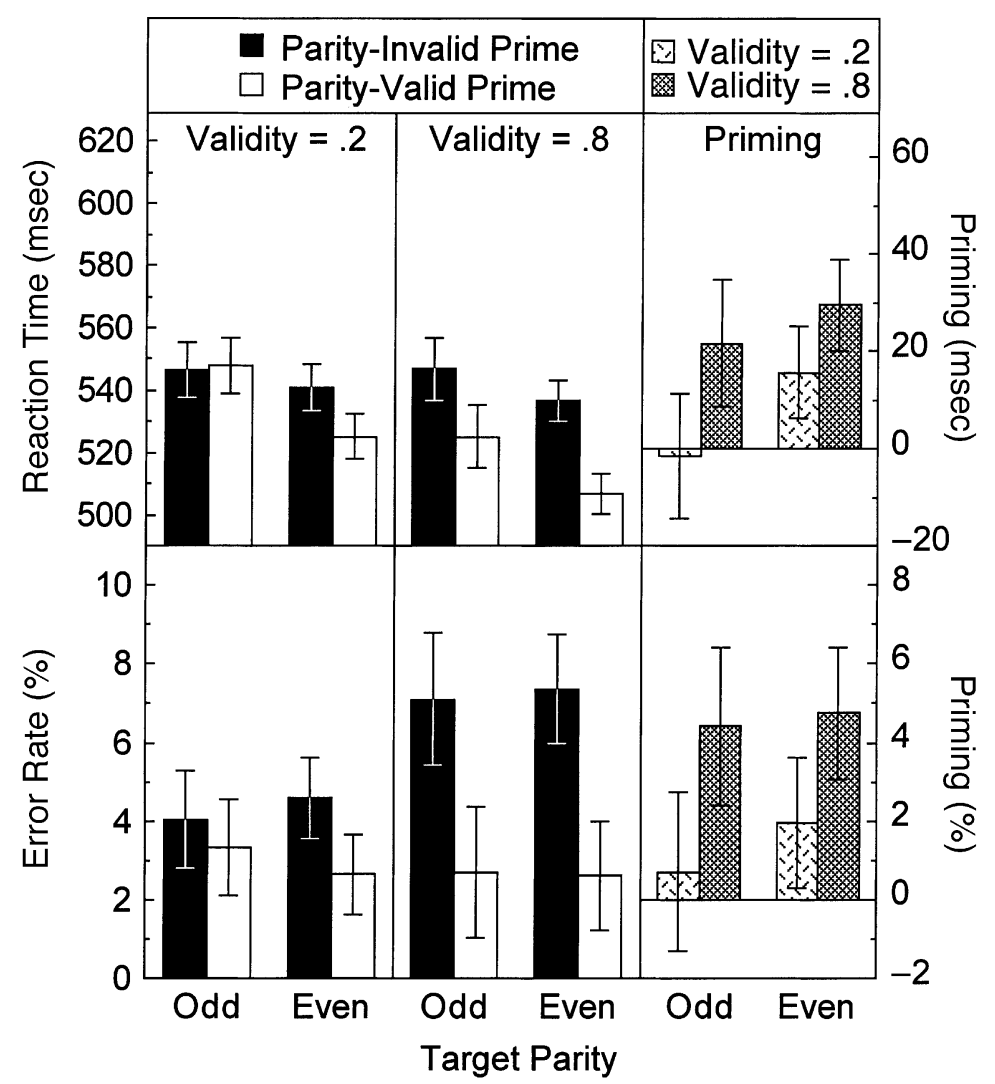

Figure 2. Experiment 2: Mean reaction time, error rate, and priming effect for odd and even targets as functions of prime type and prime validity.

aware that something other than a row of Xs appeared before targets was identical to that of Experiment 1 (30\% of the .8 -valid group and $45 \%$ of the .2 -valid group).

Reaction times. The key findings from Experiment 1 were replicated: Parity-valid priming occurred and was far greater for the .8- than for the .2-valid group. Followup tests showed that priming was robust in the .8 valid group [26 msec; $\left.F(1,19)=61.03, M S_{\mathrm{e}}=107\right]$ but was only marginally significant in the .2 -valid group $\left[7 \mathrm{msec} ; F(1,19)=3.58, M S_{\mathrm{e}}=141, p=.07\right]$.

Error rates. The error-rate analyses supported the reaction-time analyses; reductions in errors on parityvalid trials were reliably greater when prime validity was .8 rather than .2 . Priming was reliable in both the .8 -valid group $\left[4.6 \% ; F(1,19)=27.67, M S_{\mathrm{e}}=7.58\right]$ and the $.2-$ valid group $\left[1.3 \% ; F(1,19)=6.69, M S_{\mathrm{e}}=2.64\right]$.

\section{Discussion}

In replication of Experiment 1, parity judgments were facilitated on parity-valid trials relative to parity-invalid trials, although parity-valid primes were further from their targets. Most importantly, parity-valid priming was again greater in the .8 -valid group than in the .2-valid group, this time with digit stimuli and a $42-\mathrm{msec}$ SOA. This prime-validity effect occurred without the presence of repetition-prime trials in the .8-valid group. Experiments 1 and 2 support the claim that the influence of masked primes is greater when the primes are more likely to be useful for performing the target task.

\section{EXPERIMENT 3 \\ Parity Versus Magnitude Judgments With Digit Stimuli}

It is risky to refer to "the influence of a prime" without considering the nature of the target task, just as it is risky to refer to the impact of an encoding experience without considering the nature of the memory test (e.g., Morris et al., 1977). The context-sensitive nature of memory task performance has long been known (e.g., Tulving \& Thomson, 1973), yet only recently have studies investigated the influence of task variables on masked priming (e.g., Greenwald et al., 2003; Klinger et al., 2000; Kunde, Kiesel, \& Hoffman, 2003; Naccache et al., 2002).

The goal of Experiment 3 was to show conclusively that the influence of a number prime depends critically on the target task and on the validity of the primes for performing that task. To this end, the usefulness of a prime for making an odd/even parity judgment was placed in opposition to its usefulness for making a less- 
Table 2

Experiments 3 and 4: Prime-Target Pairs

\begin{tabular}{|c|c|c|c|c|c|c|c|}
\hline \multicolumn{4}{|c|}{ Parity-Valid/Magnitude-Invalid Trials } & \multicolumn{4}{|c|}{ Magnitude-Valid/Parity-Invalid Trials } \\
\hline \multicolumn{2}{|c|}{ Odd Targets } & \multicolumn{2}{|c|}{ Even Targets } & \multicolumn{2}{|c|}{ Odd Targets } & \multicolumn{2}{|c|}{ Even Targets } \\
\hline $1-4$ & $6-9$ & $1-4$ & $6-9$ & $1-4$ & $6-9$ & $1-4$ & $6-9$ \\
\hline $7-1$ & $1-7$ & $6-2$ & $2-6$ & $2-1$ & $6-7$ & $1-2$ & $7-6$ \\
\hline $9-1$ & $3-7$ & $8-2$ & $4-6$ & $4-1$ & $8-7$ & $3-2$ & $9-6$ \\
\hline $7-3$ & $1-9$ & $6-4$ & $2-8$ & $2-3$ & $6-9$ & $1-4$ & $7-8$ \\
\hline $9-3$ & $3-9$ & $8-4$ & $4-8$ & $4-3$ & $8-9$ & $3-4$ & $9-8$ \\
\hline
\end{tabular}

Note-In Experiment 3, the .2-valid groups received each of the 16 valid prime-target pairs 4 times ( 64 of 320 trials $=.2$ ) and each of the 16 invalid prime-target pairs 16 times $(256$ of 320 trials $=.8)$; the reverse was true for the .8 -valid groups. In Experiment 4 , all subjects received each of the 16 valid prime-target pairs 10 times (160 of 320 trials $=.5$ ) and each of the 16 invalid prime-target pairs 10 times (160 of 320 trials $=.5$ ). Stimuli were presented as digits in both experiments.

than/more-than magnitude judgment relative to 5 . For example, $1-7$ is a parity-valid but magnitude-invalid prime-target pair, whereas $6-7$ is magnitude valid but parity invalid. Two stimulus lists differing in the ratio of these two types of trials were used (Table 2). In one list, .2 of the trials were parity valid (but magnitude invalid), and .8 of the pairs were parity invalid (but magnitude valid); this list served as the .2-valid list in the parity task and as the .8-valid list in the magnitude task. The ratio of these two kinds of prime-target pairs was reversed to form the other list that served as the .8-valid list in the parity task and as the .2 -valid list in the magnitude task. Thus, the following design was used: 2 (target type: odd vs. even in the parity task, less than 5 vs. greater than 5 in the magnitude task) $\times 2$ (prime type: parity valid vs. magnitude valid) $\times 2$ (prime validity: .2 vs. .8$) \times 2($ target judgment: parity vs. magnitude).

This design provides a strong test of the claim that the influence of a number prime depends on the task at hand. Note that for parity-valid priming to occur in the parity task (e.g., 1-7 faster than 6-7), the benefit of a parity match has to outweigh a relatively large disadvantage in magnitude match. The average prime-target distance was 5 on parity-valid trials versus 1.5 on parity-invalid trials (cf. 2 vs. 1 in Experiments 1 and 2). The memoryrecruitment account makes two key predictions: (1) the same prime-target pairs should produce parity-valid priming in the parity task but magnitude-valid priming in the magnitude task, and (2) larger priming effects should occur in each task when .8 rather than .2 of the primes are valid for performing the target task.

\section{Method}

Subjects. There were 47 subjects in the parity task: 23 in the .8 valid group and 24 in the .2 -valid group. There were 101 subjects in the magnitude task: 44 in the .8-valid group and 57 in the .2-valid group. The reason for the unequal group sizes is explained below.

Design. Targets and primes were the digits 1 to 9 , excluding 5 . Thus there were four even digits $(2,4,6,8)$ and four odd digits $(1$, $3,7,9)$, four digits were less than $5(1-4)$, and four were greater than $5(6-9)$. On parity-valid (magnitude-invalid) trials, the prime-target distance was 2, 4, 6, or $8(M=5)$. On parity-invalid (magnitudevalid) trials, the prime-target distance was either 1 or $3(M=1.5)$.
Half of the primes were greater and half were less than their target in magnitude. Table 2 shows the prime-target pairs used to construct a set of 320 trials for each subject. Primes in the left columns contain valid information about the target's parity but invalid information about the target's magnitude (e.g., 7-1, 6-2). Primes in the right columns contain valid information about the target's magnitude but invalid information about the target's parity (e.g., 2-1, $1-2)$. By orthogonally varying whether a prime was valid for making a parity or a magnitude judgment, the same prime-target pair formed a valid-prime trial given one task and formed an invalidprime trial given the other task. For example, 7 in the prime-target pair $7-1$ is exclusively parity valid, and 2 in the prime-target pair $2-1$ is exclusively magnitude valid.

Only two stimulus lists were required. Each parity-valid primetarget pair in Table 2 was sampled 16 times, and each magnitudevalid prime-target pair was sampled 4 times to produce a stimulus list that served both as the .8 -valid list in the parity task and as the .2-valid list in the magnitude task. These sampling rates were reversed to form a second stimulus list that served both as the .8-valid list in the magnitude task and as the .2-valid list in the parity task. Trials were divided into two blocks of 160 trials with 80 of each target type per block. Prime validity was the same in each block. The order of trials within each block was randomized for each subject.

Procedure. The procedure was same as in Experiment 2, except that the subjects tested in the magnitude task pressed the left button ("less") with their left index finger to indicate that the target was less than 5 and pressed the right button ("more") with their right index finger to indicate that the target was greater than 5. The SOA was $42 \mathrm{msec}$.

\section{Results}

Reported prime awareness. In Experiment 3, we set quotas of 20 and 40 unaware subjects per group in the parity and magnitude tasks, respectively, so that our analyses of prime-validity effects in the stricter unaware data sets were based on groups of equal and substantial size. To attain the parity task quota, 23 subjects were tested in the .8-valid group (13\% were aware), and 24 were tested in the .2 -valid group (17\% were aware). To reach the magnitude task quota, 44 subjects were tested in the .8 -valid group ( $9 \%$ were aware), and 57 were tested in the .2-valid group (30\% were aware). With the exception of the last group, prime awareness was somewhat lower than in Experiments 1 and 2. The chief results were again the same whether analyses were con- 


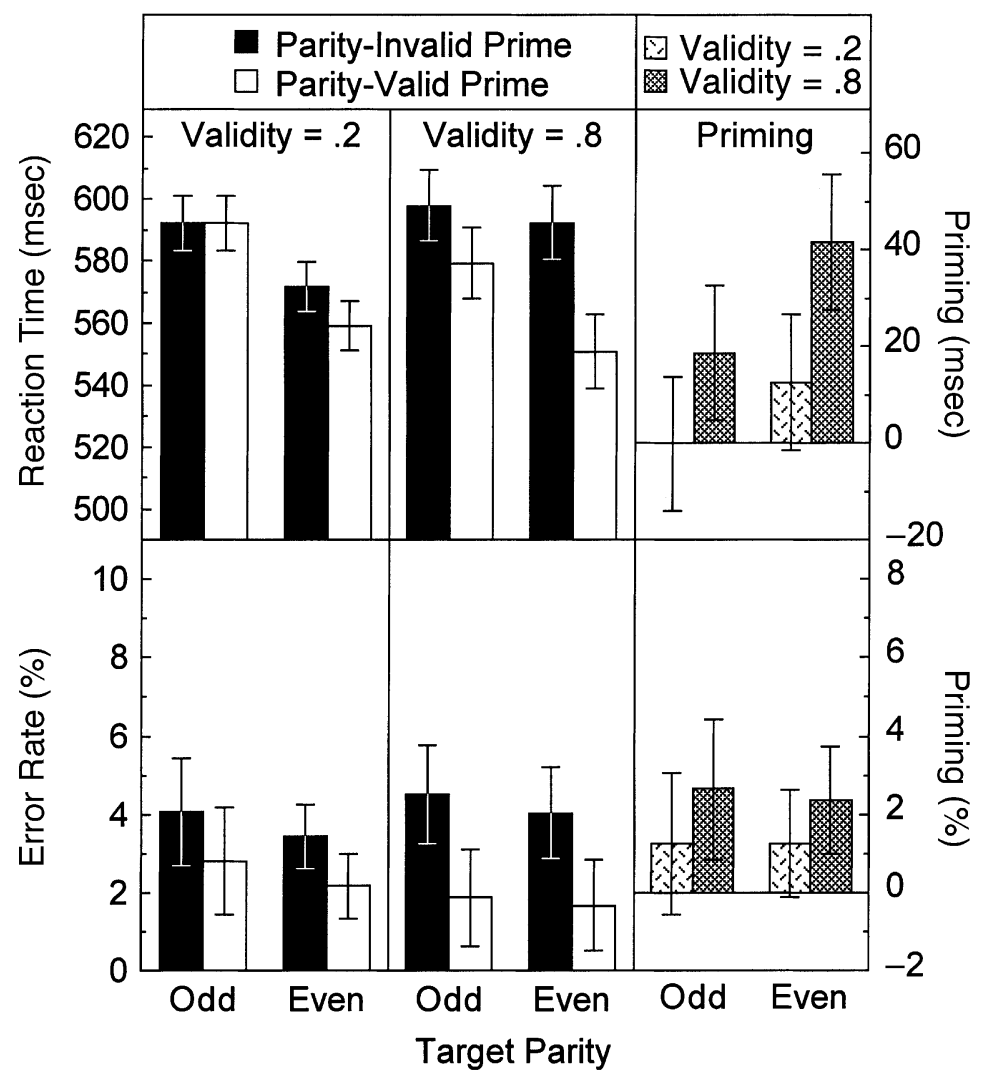

Figure 3. Experiment 3 (parity task): Mean reaction time, error rate, and priming effect for odd and even targets as functions of prime type and prime validity.

ducted on the full or unaware data sets. Prime awareness is further examined in Experiment 4.

Parity task data. Figure 3 displays the mean reaction time and error rates, and their confidence intervals, based on the full data set, for the .2-valid and .8-valid groups that were given the parity task. The ANOVAs were the same as those used in Experiment 2 (Appendix B).

Reaction times. As expected, responses were faster on parity-valid trials (mean prime-target distance of 5) than on parity-invalid trials (mean prime-target distance of $1.5)$, clearly showing that masked priming of parity judgments is driven by the prime's validity for making a parity judgment to the target rather than by similarity in magnitude. Moreover, as predicted by the memoryrecruitment account, parity-valid priming was greater when the proportion of parity-valid trials was .8. When .8 of the trials were parity valid, there was $29 \mathrm{msec}$ of parityvalid priming $\left[F(1,22)=29.92, M S_{\mathrm{e}}=321\right]$, whereas when .2 of the trials were parity valid, the 6 -msec parityvalid priming effect was only marginal $[F(1,23)=3.37$, $\left.M S_{\mathrm{e}}=141, p=.08\right]$.

Error rates. Only the priming effect was significant, reflecting fewer errors on parity-valid trials than on parity-invalid trials.

Magnitude task data. Figure 4 displays the mean reaction time and error rates and their confidence intervals for the .2-valid and .8-valid groups that were given the magnitude task. Analyses were the same as in the parity task (Appendix B), except that the two levels of the target type factor were less than 5 (1 to 4 ) and greater than 5 (6 to 9).

Reaction times. The .2- and .8-valid groups received the same stimulus list shown to the .8- and .2-valid groups in the parity task, respectively. When making magnitude judgments, the cognitive system should benefit from a match in prime-target magnitude more than from a match in prime-target parity. If so, reaction times should be faster on magnitude-valid than on magnitude-invalid trials (i.e., faster on parity-invalid than on parity-valid trials) the opposite of what was found in the parity task-especially when most of the trials are magnitude valid. These predictions of the memory-recruitment account were fully supported: Magnitude-valid priming occurred and was reliably greater for the .8-valid group. Magnitude-valid priming was significant in the .8-valid group [27 msec; $\left.F(1,43)=78.28, M S_{\mathrm{e}}=202\right]$ and in the .2 -valid group $\left[17 \mathrm{msec} ; F(1,56)=56.72, M S_{\mathrm{e}}=146\right]$.

Error rates. The pattern in the error rates echoed the pattern in the reaction times. There were fewer errors on magnitude-valid than on magnitude-invalid trials, and magnitude priming was greater in the .8 -valid group. Magnitude-valid priming was significant in the .8 -valid group $\left[2.8 \% ; F(1,43)=24.96, M S_{\mathrm{e}}=7.02\right]$ but only mar- 


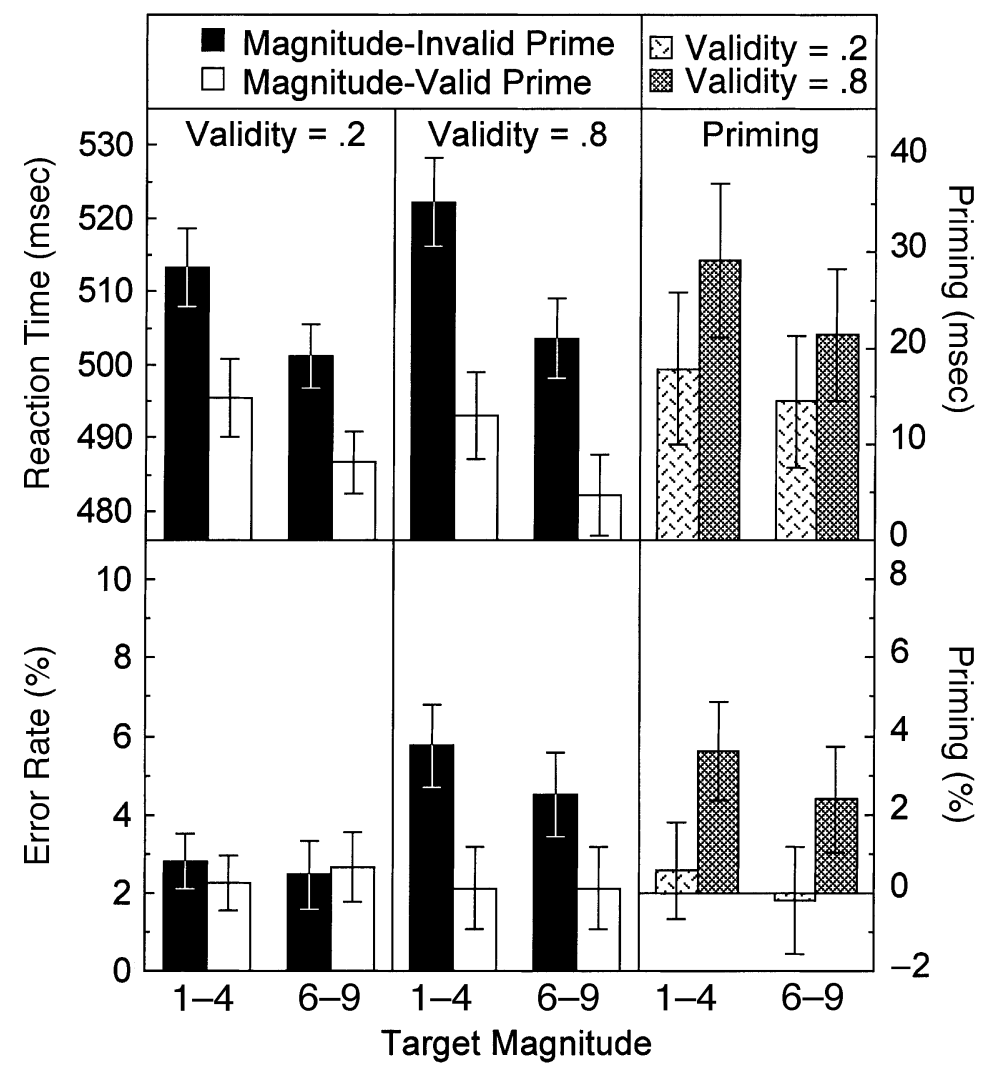

Figure 4. Experiment 3 (magnitude task): Mean reaction time, error rate, and priming effect for targets less than 5 or greater than 5 as functions of prime type and prime validity.

ginal in the .2 -valid group $\left[0.6 \% ; F(1,56)=3.21, M S_{\mathrm{e}}=\right.$ $3.35, p=.08]$.

\section{Discussion}

In Experiment 3, the influence of the same set of masked primes on the same set of targets depended on how subjects were instructed to process the targets. In the parity task, parity-valid primes facilitated responses relative to parity-invalid primes (e.g., 1 was a better prime than 6 for the target 7), extending the effect reported in Experiments 1 and 2 and in Reynvoet et al. (2002) to more extreme prime-target distances. In contrast, when subjects made magnitude judgments to the same stimuli, the opposite pattern was found (e.g., 6 was now a better prime than 1 for the target 7), consistent with previous results (e.g., Dehaene et al., 1998; Koechlin et al., 1999; Naccache et al., 2002; Naccache \& Dehaene, 2001;). Klinger et al. (2000, Experiment 4) reported a task-dependent reversal in the influence of the same set of masked primes on the same set of targets with word stimuli. Experiment 3 represents the first such demonstration with number stimuli, while further showing the dependence of masked priming on the list-wide prime validity. In the General Discussion section, we evaluate several interpretations of prime-validity effects, but first we reinforce our claim that these effects are not likely due to awareness of the primes.

\section{EXPERIMENT 4}

\section{Tests of the Influence of Awareness on Priming}

Thirty-nine percent of the subjects in Experiments 1-3 reported being at least occasionally aware that another stimulus appeared between the mask and the target. This level of prime awareness is not unprecedented with number stimuli (e.g., 44\% in Naccache \& Dehaene, 2001, Experiment 1;28\% in Koechlin et al., 1999). The prime-validity effects in Experiments 1-3 were little affected by excluding prime-aware subjects, a precaution also taken in other masked priming studies (e.g., Bodner \& Masson, 2003, 2004; Jaskowski et al., 2003; Koechlin et al., 1999; Naccache \& Dehaene, 2001). Although no studies to date have found qualitatively different patterns of masked priming effects for subjectively prime-aware subjects versus prime-unaware subjects, it is debatable whether subjective reports should be taken as the gold standard of awareness (e.g., Cheesman \& Merikle, 1986; Holender, 1986; Merikle, Smilek, \& Eastwood, 2001). Following a block of priming trials, some recent studies have included another block of trials in which subjects' 
awareness of the primes is measured by having them make judgments about the masked primes. Several studies have reported that masked priming effects are not correlated with accuracy in various prime-judgment tasks (Bodner \& Masson, 2003; Damian, 2001; Jaskowski et al., 2003; Naccache \& Dehaene, 2001).

In Experiment 4, subjects made either parity or magnitude judgments in two blocks of trials. Subjects were not informed of the primes in the first block, and parity or magnitude judgments were made to the targets as in Experiment 3. In the second block, subjects were informed of the primes and attempted to make the same judgment about the masked primes (e.g., Naccache \& Dehaene, 2001). Target-task priming was then correlated with prime-task accuracy. To obtain an unbiased measure of prime-task accuracy, the target response could not be predictive of the correct prime response; therefore, prime validity was set at .5 in both blocks.

\begin{abstract}
Method
Subjects. Twenty subjects made parity judgments, and 20 made magnitude judgments.

Design. The same prime-target pairs were used as in Experiment 3 . The 32 prime-target pairs in Table 2 were presented 5 times in the 160-trial target-task block and 5 times in the 160-trial primetask block. Thus, the same .5-valid list was used to form both blocks of trials for both target-task groups. The order of trials within each block was randomized for each subject.

Procedure. The target-task block was conducted as in Experiment 3 . The subjects were then asked the usual prime-awareness question. This time, prime-aware subjects were further classified into those who reported seeing digit primes and those who only reported seeing "something flicker." The subjects were then informed of the presence of the primes and were told that in the next block of trials they would make the same judgment about the masked primes. They were told that the task would be very challenging and that they should make their best effort and not worry if they could not see any of the primes. To encourage the subjects to try their best, they were correctly informed that they would be shown their accuracy at the end of the task. Accuracy feedback was not given during the prime task. After this task, the subjects were asked whether they felt that they were correct more than $50 \%$ of the time (i.e., above chance).
\end{abstract}

\section{Results}

Reported prime awareness. Following the target task, 7 subjects in each group (35\%) reported being aware that another stimulus had appeared between the mask and target. This rate of awareness is very similar to the average across Experiments 1-3 (39\%). When prompted to provide more information about what they saw, only 2 subjects in the parity group (10\%) and 1 in the magnitude group (5\%) reported that this stimulus was another digit (the rest reported only the flickering of another stimulus). Thus, Experiments 1-3 likely overestimate the percentage of subjects who were aware that the primes were numbers. However, after the primejudgment task, $45 \%$ of the parity group and $50 \%$ of the magnitude group guessed that their accuracy was above $50 \%$ correct on this task.

Target-task priming. Parity-valid priming occurred in the parity task, and magnitude-valid priming occurred in the magnitude task. In the parity task, responses were $27 \mathrm{msec}$ faster on parity-valid than on parity-invalid trials [547 msec vs. $574 \mathrm{msec} ; F(1,19)=46.89, M S_{\mathrm{e}}=310$ ], but there was no difference in error rates $[4.9 \%$ vs. $4.5 \%$; $F<1]$. In the magnitude task, responses were $30 \mathrm{msec}$ faster on magnitude-valid than on magnitude-invalid trials $\left[459 \mathrm{msec}\right.$ vs. $\left.489 \mathrm{msec} ; F(1,19)=53.53, M S_{\mathrm{e}}=335\right]$ and were $2.0 \%$ more accurate $[1.9 \%$ vs. $3.9 \% ; F(1,19)=9.22$, $\left.M S_{\mathrm{e}}=8.7\right]$.

Prime-task accuracy. Although less than $50 \%$ of the subjects felt that they were above chance on the prime task, objectively, $75 \%$ of the parity subjects and $80 \%$ of the magnitude subjects were numerically above chance. The mean accuracy (averaged over both target types in each task to control for response bias) was above chance in both the parity group $[56 \% ; t(19)=3.89]$ and magnitude group $[58 \% ; t(19)=4.19]$.

Relation between prime-task accuracy and targettask priming. We obtained a wide range of target-task priming values; moreover, all but one subject per group showed target-task priming, and $77.5 \%$ were above chance on the prime task. Despite these conditions, the correlation between priming and prime-task accuracy was not significant overall $(r=-.11, p<.52)$ or within the parity or magnitude task $(r=-.03, p<.92 ; r=-.19, p<.43)$.

\section{Discussion}

Greater prime-task accuracy was not associated with larger masked priming effects in either task, consistent with previous tests (Bodner \& Masson, 2003; Damian, 2001; Jaskowski et al., 2003; Naccache \& Dehaene, 2001; Neumann \& Klotz, 1994). Furthermore, removing prime-aware subjects produced little change in the prime-validity effects in Experiments 1-3. It therefore seems unlikely that our effects were produced by conscious awareness of the primes. Moreover, as Naccache and Dehaene (2001) pointed out, above-chance primetask performance "does not necessarily imply conscious perception, because subjects' performance . . might have been contaminated by unconscious processes" (p. 221), just as unconscious memory processes have been shown to contribute to performance on explicit memory tests (e.g., Jacoby, Toth, \& Yonelinas, 1993). The prime task very likely overestimates subjects' awareness of the primes during the earlier target task because subjects are informed of the presence of the primes before the prime task and are encouraged to ignore the targets and to focus their attention on trying to see the primes. Even under these conditions, only $47.5 \%$ of subjects felt that they were above chance on the prime task, although numerically $77.5 \%$ were above chance. Hence, some subjects who felt that they were guessing on the prime task were nonetheless above chance.

\section{GENERAL DISCUSSION}

The influence of masked primes on number processing was shown to depend on the likelihood that the prime 
contains useful information for responding to the target in the task at hand. Odd/even parity judgments with number words (Experiment 1) and Arabic digits (Experiments 2-4) were facilitated by primes of matching parity (although these were numerically farther from their targets), and this parity-valid priming effect was greater when .8 rather than .2 of the trials were parity valid (Experiments 1-3). In Experiment 3, a reversal in the direction of priming was found for the same set of prime-target pairs, depending on the task. Here, each prime-target pair was exclusively parity valid (e.g., 1-7) or magnitude valid relative to a standard of 5 (e.g., 6-7). When subjects made parity judgments, responses were again facilitated on parity-valid trials, especially when .8 of the trials were parity valid. Conversely, when subjects made magnitude judgments, responses were now facilitated on magnitude-valid (i.e., parity-invalid) trials, especially when .8 of the trials were magnitude valid. Awareness of masked primes was not responsible for these effects: Removal of prime-aware subjects did not eliminate these prime-validity effects (Experiments 1-3), and higher prime-task accuracy was not associated with larger priming effects (Experiment 4).

The occurrence of prime-validity effects with masked primes suggests that people can respond adaptively to contextual elements of which they are unaware. Primevalidity effects have now been shown with numbers (Experiments 1-3), words (Bodner \& Masson, 2001, 2003, 2004), and nonalphanumeric stimuli (Jaskowski et al., 2003), implicating a domain-general mechanism. In the next section, we describe an important property of prime-validity effects that constrains potential explanations, which are then evaluated in the remaining sections.

\section{Prime Validity Manipulations Produce a Bias Effect}

An adaptive cognitive system should rely on masked primes to a greater extent when they are more likely to facilitate target responding. The validity of a prime on a particular trial cannot usually be known until the target is presented; therefore, the cognitive system must set its level of prime reliance on the basis of information it computes across trials. An increased reliance on primes when prime validity is high should therefore produce a benefit on valid-prime trials as well as a cost on invalidprime trials - a bias effect (e.g., Ratcliff \& McKoon, 1997; Ratcliff, McKoon, \& Verwoerd, 1989). To test whether increased prime validity produced a bias effect, we pooled all of the parity-task data from Experiments $1-3(n=127)$ to increase power and computed the mean reaction time and error rate within each condition, averaged across target type (shown in Figure 5A, which is representative of Experiments 1-3; see Figures 1-3). One-way ANOVAs were then used to examine the effects of prime validity.

In the reaction time analyses, the .8-valid group was $22 \mathrm{msec}$ faster than was the .2-valid group on parityvalid trials $\left[F(1,125)=4.35, M S_{\mathrm{e}}=3,530\right]$. The .8 -valid group thus benefited more from valid primes than did the .2-valid group - a facilitation effect (see Figure 5A). This effect contrasts with claims that masked priming of number judgments is primarily due to interference on invalid trials (e.g., Koechlin et al., 1999; Naccache \& Dehaene, 2001); indeed, the .8-valid group was only $1 \mathrm{msec}$ slower than was the .2-valid group on invalid trials $(F<$ 1). An interference effect did emerge in the error rate analyses, however: The .8 -valid group made $2.2 \%$ more errors than did the .2-valid group on parity-invalid trials $\left[F(1,125)=11.00, M S_{\mathrm{e}}=14.2\right]$. There was only a $0.4 \%$ difference in error rates between the .8 - and .2-valid groups on parity-valid trials $(F<1)$, a result that mirrored the reaction time data. An increase in prime validity thus induced a bias effect.

Bodner and Masson (2001), using the same design and procedure, found greater masked repetition priming for words in the lexical decision task when prime validity was .8 rather than .2 . Figure $5 \mathrm{~B}$ shows the form of this prime-validity effect, averaged across eight data sets. Bodner and Masson (2001) found that the .8 group was faster than the .2 group on valid (i.e., repetition) prime trials (a facilitation effect), but also made more errors on invalid (i.e., unrelated) prime trials (an interference effect). The bias pattern with words is very similar to that obtained with numbers. This similarity is striking considering that (1) there were no response-invalid primes in the lexical decision task (and hence no possibility of response priming), and (2) each prime and target appeared only once in the lexical decision task (vs. multiple times in the parity task).

Prime validity also induces a bias effect in a left/right judgment task with nonalphanumeric stimuli. As can be seen in Figure 5C, Jaskowski et al. (2003) found that subjects benefited more from side-valid than side-invalid primes when prime validity was .8 rather than .2 . When .8 of the trials were side valid, responses were faster on sidevalid trials (a facilitation effect) but were slower and more error-prone on side-invalid trials (interference effects). ${ }^{2}$

In summary, in several tasks and stimulus domains, a high level of prime validity facilitates responses on valid trials but also impairs responses when the less frequent invalid trials arise. When the frequent benefits of relying on the primes outweigh the infrequent costs (i.e., in the .8valid conditions), the cognitive system appears to increase its reliance on the primes. When reliance on the primes works against efficient task performance (i.e., in the .2valid conditions), prime reliance decreases. Under both conditions, subjects adapt efficiently to the prime context's utility. Next, we consider how well prime-validity effects of the bias form described here fit with a variety of accounts of priming.

\section{Evaluation of Activation-Based Accounts}

In the parity task, parity-valid primes further away from their targets produced more facilitation than did parity-invalid primes closer to their targets (Experiments 1-4; Reynvoet et al., 2002). This finding does not rule out the possibility that masked primes automatically ac- 


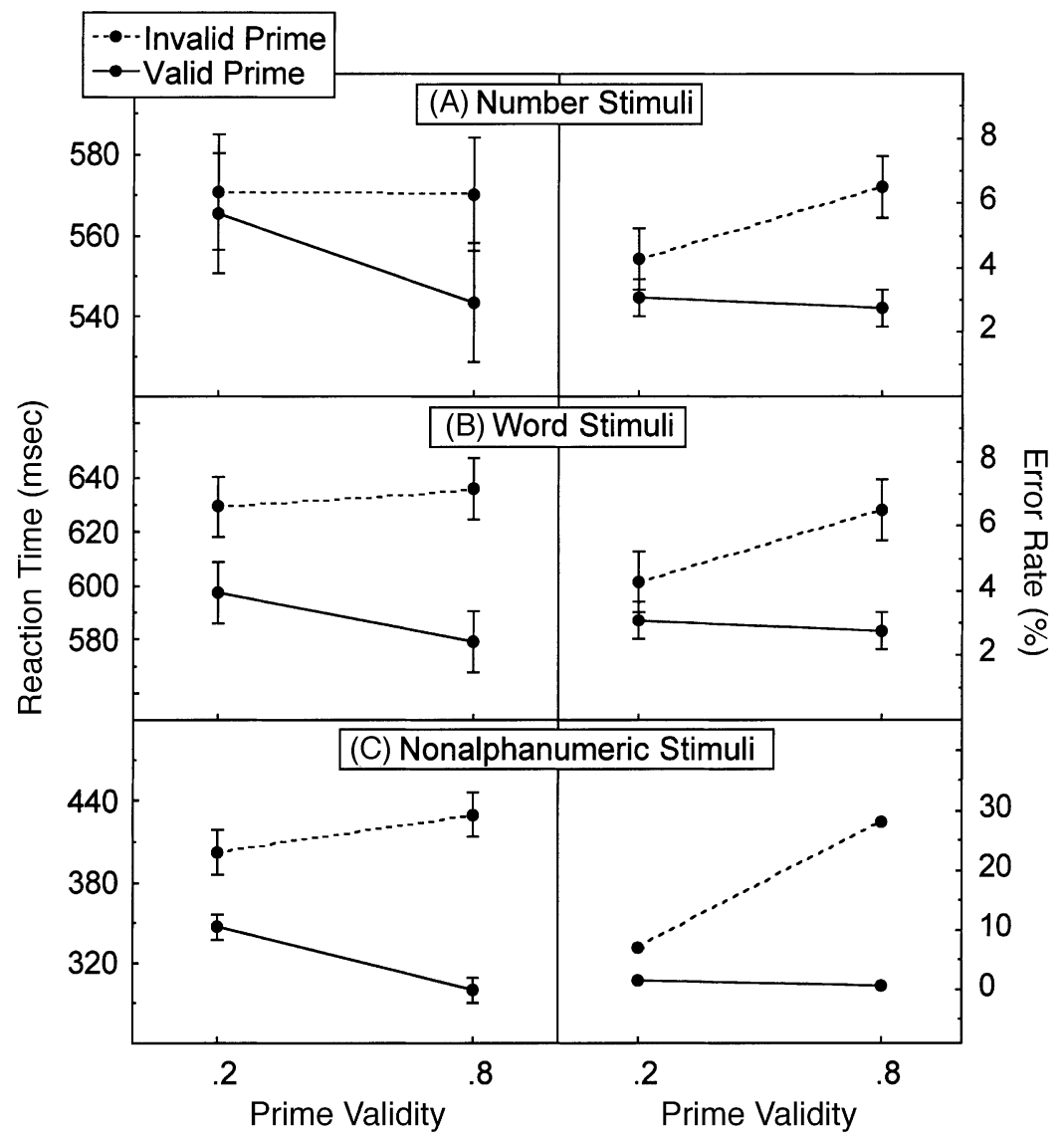

Figure 5. Effects of prime validity on mean reaction times and error rates for (A) number stimuli (parity task; data pooled across target type and Experiments 1-3), (B) word stimuli (lexical decision task; word data pooled across eight sets of repetitionpriming data, adapted from Bodner \& Masson, 2001), and (C) nonalphanumeric stimuli (left/right task; adapted from Jaskowski, Skalska, \& Verleger, 2003, Experiment 3). Error bars (too small to be visible for error rate means in bottom panel) are $\mathbf{9 5 \%}$ between-subjects (A and B) or within-subjects (C) confidence intervals, computed separately for valid and invalid trials, and are appropriate for comparing a given trial type across prime-validity conditions.

tivate abstract number line representations (e.g., Reynvoet \& Brysbaert, 1999; Reynvoet et al., 2002) or magnitude representations (e.g., Koechlin et al., 1999). The present experiments do not focus on distance priming, but several studies have shown that distance priming (e.g., 7 primes 9 better than 5 primes 9) occurs even in the parity task where magnitude is irrelevant (e.g., Dehaene, Bossini, \& Giraux, 1993; Reynvoet \& Brysbaert, 1999; Reynvoet et al., 2002; Sudevan \& Taylor, 1987), although numbers may not automatically activate their magnitude representations under all conditions (see Naccache et al., 2002; Pansky \& Algom, 2002). Whether distance priming is influenced by task and prime validity remains to be investigated. Instead, our parity experiments show that whether or not a prime is parity-valid has a greater influence on priming than does prime-target distance. The task-dependent reversal in the direction of priming in Experiment 3 casts further doubt on the view that priming effects with numbers are primarily the result of context- and task-independent activation processes (e.g., Greenwald et al., 2003; Kunde et al., 2003; Naccache et al., 2002).

Finally, prime-validity effects on the bias form shown in Figure 5 may be difficult to explain using a purely activation-based mechanism (e.g., Dehaene et al., 1998; Reynvoet \& Brysbaert, 1999) unless a major revision of the concept of automatic activation is made. For example, one could postulate that activation increases when prime validity is .8 , which would account for the increase in facilitation on valid trials when prime validity is .8 rather than .2. However, this revision would not account for the increase in interference on invalid trials in the .8 groups, because automatic spreading activation does not produce interference (e.g., Collins \& Loftus, 1975). Task- and validity-dependent priming of the bias form shown here thus challenge the notion that masked priming predominantly reflects a prospective, activation- 
based mechanism (see also Bodner \& Masson, 2003; Greenwald et al., 2003; Klinger et al., 2000).

\section{Evaluation of a Response-Priming Account}

Our valid primes always matched the correct target response, whereas our invalid primes never did. This provided us with a simple means of evaluating the taskdependent influence of prime validity, but it also makes it tempting to attribute our results to a response-priming mechanism. That is, perhaps subjects categorized the masked primes in a task-dependent way, thus priming the wrong motor response on invalid trials (e.g., Dehaene et al., 1998; Neumann \& Klotz, 1994). Such an account is compatible with most of the priming effects we report. However, it cannot explain why repetition priming was greater than response-valid priming in Experiment 1 (see also Naccache \& Dehaene, 2001), nor can it explain why distance priming often occurs on response-congruent trials (e.g., Koechlin et al., 1999; Naccache \& Dehaene, 2001; Reynvoet \& Brysbaert, 1999; Reynvoet et al., 2002).

It is also unclear how a response-priming account could explain prime-validity effects. Greater interference might be expected in the .2-valid group because those subjects received four times more response-invalid trials, yet the .8-valid group showed more interference (in the error rates). In addition, why the .8 -valid group showed more facilitation from response-valid primes would need to be explained. Alternatively, the .2-valid groups might set higher thresholds for triggering a response to prevent invalid primes from triggering incorrect responses, or equivalently, the .8-valid groups might lower their response thresholds to capitalize on a high level of prime validity. However, if the .2-valid groups raised their response thresholds, they should have taken longer to respond (or made fewer errors) than did the .8-valid groups on both invalid and valid trials, because more time would be needed to accumulate enough information to reach one of the response thresholds. The threshold argument thus predicts main effects of prime validity, rather than the observed interactions of prime validity and priming.

A response-priming account is further challenged by the finding of prime-validity effects of the same form whether response-incongruent trials were present (Figures $5 \mathrm{~A}$ and $5 \mathrm{~B}$ ) or not (Figure 5B). These and other results (e.g., Kunde et al., 2003) suggest that the scope and/or scale of response-priming effects may have been overestimated (see also Greenwald et al., 2003).

\section{Evaluation of a Target-Response Association Account}

Damian (2001) argued that when the same primes and targets appear on multiple trials, subjects learn a response association for each target (e.g., $3=$ odd, $6=$ more-than5 ). When a practiced target then serves as a masked prime, its learned response is automatically recruited, causing facilitation on response-valid trials and/or interference on response-invalid trials, as was observed in Experiments 1-4. Although Damian found results consistent with this target-response association account, Abrams, Klinger, and Greenwald (2002) obtained masked priming of pleasantness judgments by congruent primes even when the response required of the target differed from the response that the subject had consciously learned to make to the prime (see also Abrams \& Greenwald, 2000). Moreover, masked priming of judgments including pleasantness (e.g., Abrams et al., 2002), magnitude (Greenwald et al., 2003; Kunde et al., 2003; Naccache \& Dehaene, 2001), and parity (Reynvoet et al., 2002) can occur even for primes that were never presented as targets, and hence for which no learning of stimulus-response mappings had occurred. In our experiments, both validity groups received the same set of targets and thus received the same amount of practice at learning stimulus-response mappings for each target, yet the .8-valid groups consistently showed more priming. It is unclear how target-response learning could explain the present prime-validity effects, or why the bias effect is the same whether each stimulus is presented once or multiple times (Figure 5).

\section{Evaluation of a Prime-Response Association Account}

A variant of the previous account is that our subjects might have unconsciously learned to associate particular masked primes with particular responses because primes were associated with certain responses more than others in Experiments 1-3 (see Tables 1 and 2). Moreover, the .8-valid groups typically received more exposures to each valid prime-target pair than did the .2-valid groups, and thus may have formed stronger associations. Could learned prime-response associations explain our primevalidity effects? We suggest this is unlikely.

If priming solely reflects learned prime-response associations, the .2-valid groups should have learned to associate each prime with the opposite response. For example, in Experiments 1 and 2, the prime 3 occurred with the target 5 on 6 trials but occurred with the target 4 on 24 trials; thus, the .2-valid group should have learned to associate the prime 3 with an even response. If such associations had been formed, the .2-valid groups should have been faster or more accurate on parity-invalid trials than on parity-valid trials, but this never occurred. More definitively, primes were not predictive of target responses in Experiment 4 (see Table 2), yet robust task-specific priming effects were observed. For example, 3 was associated with even/less-than- 5 targets ( 2 and 4 ) and with odd/ greater-than-5 targets ( 7 and 9 ) equally often. Finally, this account cannot explain why prime-validity effects occur in tasks where each prime and target are presented only once (Bodner \& Masson, 2001, 2003, 2004).

\section{Evaluation of a Differential-Attention Account}

Naccache et al. (2002) found that masked priming was eliminated if subjects did not pay attention to the stimulus display when each prime-target pair was presented. Naccache et al. suggested that the processes that contribute to masked priming require attention and that the 
task context and other variables (e.g., prime validity) might influence how much attention is focused on the masked primes. Thus, the .2 -valid groups might simply learn to pay less attention to the primes than the .8-valid groups would. This differential-attention account can explain the weak priming effects in the .2 -valid groups, their slower responses on valid-prime trials, their greater accuracy on invalid-prime trials, the occurrence of primevalidity effects across stimulus domains, and the similarity of prime-validity effects whether or not responseincongruent trials are present.

The present experiments do not allow us to determine whether the .2-valid groups paid less attention to the primes than did the .8 -valid groups. The possibility that the cognitive system adapts to prime validity by modulating the amount of attention focused on the processing of the masked prime event thus remains an intriguing hypothesis worthy of further investigation. We note here one potential challenge to this account, however. Masson and Bodner (2003) found that a masked repetition prime presented on trial $n$ primed lexical decisions to a target presented on trial $n+1$. If the cognitive system learns to ignore prime displays that are not useful for responding to targets presented during the same processing window, it should not have paid attention to these masked primes because the within-trial prime validity was zero.

\section{Evaluation of a Memory-Recruitment Account}

The differential-attention account and the memoryrecruitment account proffer similar explanations for prime-validity effects, except that the former claims that attention-based prime encoding is more likely when prime validity is high, whereas the latter claims that memory-based prime recruitment is more likely. The differential-attention account cannot be ruled out on grounds of parsimony alone, but an attractive feature of the memory-recruitment account is that it explains both priming and prime-validity effects, whereas the differentialattention account requires an additional mechanism to explain how priming occurs.

The main premise of the memory-recruitment account is that each masked prime event is encoded into a new memory representation (an episodic record that is usually too weak to be consciously accessed) that can later be recruited to assist with target processing. Priming is characterized as a skill-transfer effect (e.g., Poldrack \& Gabrieli, 2001) in which target processing benefits from the recruitment of the similar processing operations applied to the prime in the specific context at hand. This view of priming has been supported by a number of studies (e.g., Bodner \& Masson, 1997, 2001, 2003, 2004; Hughes \& Whittlesea, 2003; Masson \& Bodner, 2003; Masson \& Isaak, 1999; Whittlesea \& Jacoby, 1990) and is consistent with various learning-based accounts of priming (e.g., Becker, Moscovitch, Behrmann, \& Joordens, 1997; Joordens \& Becker, 1997; Kolers, 1973, 1975, 1976; Logan, 1988; Ratcliff \& McKoon, 1988, 1994).
Our goal here has been to suggest that the memoryrecruitment account can contribute to our understanding of how numbers are processed. The memory-recruitment account highlights the usefulness of viewing priming, even masked priming, as influenced by contextual factors such as prime validity in a wide range of tasks and stimulus domains. The claim that prime recruitment increases when prime validity is high also explains both the greater facilitation on valid trials (benefit of increased reliance) and the greater interference on invalid trials (cost of increased reliance) shown in Figure 5. Dehaene et al. (1993) acknowledged the possibility of memory-based contributions to number processing when they suggested that "parity information is retrieved from memory together with a number of other semantic properties" (p. 376). Moreover, Koechlin et al. (1999) speculated that subjects in a magnitude task might encode masked primes using the labels smaller and larger. Our demonstrations of task- and validity-dependent priming are in keeping with notions like these.

\section{CONCLUSION}

Current evidence suggests that our cognitive systems have the ability to tune into the usefulness of a contextual element of which we are not aware, such as a masked prime, and to increase or decrease the use of this element to maximize task performance. We suggest that a memoryrecruitment account provides a useful way of characterizing both the process of priming and the attunement to prime validity, albeit at a rather general level. The intriguing possibility that unconscious processes can be flexible and adaptive will likely face many more tests, and the balance of these tests will ultimately determine its validity.

\section{REFERENCES}

Abrams, R. L., \& Greenwald, A. G. (2000). Parts outweigh the whole (word) in unconscious analyses of meaning. Psychological Science, 11, 118-124.

Abrams, R. L., Klinger, M. R., \& Greenwald, A. G. (2002). Subliminal words activate semantic categories (not automated motor responses). Psychonomic Bulletin \& Review, 9, 100-106.

Allen, S. W., \& JACOBY, L. L. (1990). Reinstating study context produces unconscious influences of memory. Memory \& Cognition, $\underline{\mathbf{1 8}}$, 270-278.

Becker, S., Moscovitch, M., Behrmann, M., \& Joordens, S. (1997). Long-term semantic priming: A computational account and empirical evidence. Journal of Experimental Psychology: Learning, Memory, \& Cognition, 23, 1059-1082.

BoDNER, G. E., \& MASSON, M. E. J. (1997). Masked repetition priming of words and nonwords: Evidence for a nonlexical basis for priming. Journal of Memory \& Language, 37, 268-293.

Bodner, G. E., \& Masson, M. E. J. (2001). Prime validity affects masked repetition priming: Evidence for an episodic resource account of priming. Journal of Memory \& Language, 45, 616-647.

Bodner, G. E., \& Masson, M. E. J. (2003). Beyond spreading activation: An influence of relatedness proportion on masked semantic priming. Psychonomic Bulletin \& Review, 10, 645-652.

Bodner, G. E., \& Masson, M. E. J. (2004). Beyond binary judgments: Prime validity modulates masked repetition priming in the naming task. Memory \& Cognition, 32, 1-11. 
Brysbaert, M. (1995). Arabic number reading: On the nature of the numerical scale and the origin of phonological recoding. Journal of Experimental Psychology: General, 124, 434-452.

BRYSBAERT, M. (2001). Prelexical phonological coding of visual words in Dutch: Automatic after all. Memory \& Cognition, 29, 765-773.

Cheesman, J., \& Merikle, P. M. (1986). Distinguishing conscious from unconscious perceptual processes. Canadian Journal of Psychology, 40, 343-367.

Collins, A. M., \& LofTUs, E. F. (1975). A spreading-activation theory of semantic processing. Psychological Review, 82, 407-428.

Craik, F. I. M., \& Tulving, E. (1975). Depth of processing and retention of words in episodic memory. Journal of Experimental Psychology: General, 104, 268-294.

DAMIAN, M. F. (2001). Congruity effects evoked by subliminally presented primes: Automaticity rather than semantic processing. Journal of Experimental Psychology: Human Perception \& Performance, 27, 154-165.

DEHAEne, S., Bossini, S., \& GiRAux, P. (1993). The mental representation of parity and number magnitude. Journal of Experimental Psychology: General, 122, 371-396.

Dehaene, S., Naccache, L., Le Clec'H, G., Koechlin, E., Mueller, M., Dehaene-Lambertz, G., van de Moortele, P.-F., \& LE BiHan, D. (1998). Imaging unconscious semantic priming. Nature, 395, 597-600.

DEN Heyer, K., \& BRIAND, K. (1986). Priming single digit numbers: Automatic spreading activation dissipates as a function of semantic distance. American Journal of Psychology, 99, 315-340.

Forster, K. I. (1998). The pros and cons of masked priming. Journal of Psycholinguistic Research, 27, 203-233.

FoRSTER, K. I., \& DAVIS, C. (1984). Repetition priming and frequency attenuation in lexical access. Journal of Experimental Psychology: Learning, Memory, \& Cognition, 10, 680-698.

Greenwald, A. G., Abrams, R. L., Naccache, L., \& Dehaene, S. (2003). Long-term semantic memory versus contextual memory in unconscious number processing. Journal of Experimental Psychology: Learning, Memory, \& Cognition, 29, 235-247.

Greenwald, A. G., Draine, S. C., \& ABRAMS, R. L. (1996). Three cognitive markers of unconscious semantic activation. Science, $\mathbf{2 7 3}$, 1699-1702.

HighaM, P. A., \& Brooks, L. R. (1997). Learning the experimenter's design: Tacit sensitivity to the structure of memory lists. Quarterly Journal of Experimental Psychology, 50A, 199-215.

HiNes, T. M. (1990). An odd effect: Lengthened reaction times for judgments about odd digits. Memory \& Cognition, 18, 40-46.

HolENDER, D. (1986). Semantic activation without conscious identification in dichotic listening, parafoveal vision, and visual masking: A survey and appraisal. Behavioral \& Brain Sciences, 9, 1-66.

Hughes, A. D., \& Whittlesea, B. W. A. (2003). Long-term semantic transfer: An overlapping-operations account. Memory \& Cognition, 31, 401-411.

JACOBY, L. L. (1983). Perceptual enhancement: Persistent effects of an experience. Journal of Experimental Psychology: Learning, Memory, \& Cognition, 9,21-38.

JACOBY, L. L., \& DALLAS, M. (1981). On the relationship between autobiographical memory and perceptual learning. Journal of Experimental Psychology: General, 110, 306-340.

JACOBY, L. L., Toth, J. P., \& YoNELINAS, A. P. (1993). Separating conscious and unconscious influences of memory: Measuring recollection. Journal of Experimental Psychology: General, 122, 139-154.

JASKOWSKI, P., SKALSKa, B., \& VerLEGER, R. (2003). How the self controls its "automatic pilot" when processing subliminal information. Journal of Cognitive Neuroscience, 15, 911-920.

JoORDENS, S., \& BECKER, S. (1997). The long and short of semantic priming effects in lexical decision. Journal of Experimental Psychology: Learning, Memory, \& Cognition, 23, 1083-1105.

KLINGER, M. R., Burton, P. C., \& PitTs, G. S. (2000). Mechanisms of unconscious priming: I. Response competition, not spreading activation. Journal of Experimental Psychology: Learning, Memory, \& Cognition, 26, 441-455.
KLINGER, M. R., \& Greenwald, A. G. (1995). Unconscious priming of association judgments. Journal of Experimental Psychology: Learning, Memory, \& Cognition, 21, 569-581.

Koechlin, E., Naccache, L., Block, E., \& Dehaene, S. (1999). Primed numbers: Exploring the modularity of numerical representation with masked and unmasked semantic priming. Journal of Experimental Psychology: Human Perception \& Performance, $\mathbf{2 5}_{2}$ 1882-1905.

Kolers, P. A. (1973). Remembering operations. Memory \& Cognition, 1, 347-355.

Kolers, P. A. (1975). Memorial consequences of automatized encoding. Journal of Experimental Psychology: Human Learning \& Memory, 1, 689-701.

KOLERS, P. A. (1976). Reading a year later. Journal of Experimental Psychology: Human Learning \& Memory, 2, 554-565.

Kolers, P. A., \& Roediger, H. L., III (1984). Procedures of mind. Journal of Verbal Learning \& Verbal Behavior, 23, 425-449.

KUNDE, W., KIESEL, A., \& HofFMAN, J. (2003). Conscious control over the content of unconscious cognition. Cognition, 88, 223-242.

Loftus, G. R., \& Masson, M. E. J. (1994). Using confidence intervals in within-subject designs. Psychonomic Bulletin \& Review, 1, 476-490.

LogAN, G. D. (1988). Toward an instance theory of automatization. Psychological Review, 95, 492-527.

LoGAN, G. D. (1990). Repetition priming and automaticity: Common underlying mechanisms? Cognitive Psychology, 22, 1-35.

MarCEL, A. J. (1983). Conscious and unconscious perception: Experi$\underline{\text { ments on visual masking and word recognition. Cognitive Psychol- }}$ ogy, 15, 197-237.

MARCEL, T., \& FORRIN, B. (1974). Naming latency and the repetition of stimulus categories. Journal of Experimental Psychology, 103, 450460.

Masson, M. E. J., \& Bodner, G. E. (2003). A retrospective view of masked priming: Toward a unified account of masked and long-term repetition priming. In S. Kinoshita \& S. J. Lupker (Eds.), Masked priming: The state of the art (pp. 57-94). New York: Psychology Press.

MASSON, M. E. J., \& IsAAK, M. I. (1999). Masked priming of words and nonwords in a naming task: Further evidence for a nonlexical basis for priming. Memory \& Cognition, 27, 399-412.

Masson, M. E. J., \& LofTus, G. R. (2003). Using confidence intervals for graphically based data interpretation. Canadian Journal of Experimental Psychology, 57, 203-220.

Merikle, P. M., SmileK, D., \& Eastwood, J. D. (2001). Perception without awareness: Perspectives from cognitive psychology. Cognition, 79, 115-134.

MoRrIs, C. D., BRANSFORD, J. D., \& FRANKs, J. J. (1977). Levels of processing versus transfer-appropriate processing. Journal of Verbal Learning \& Verbal Behavior, 16, 519-533.

NaCcache, L., Blandin, E., \& Dehaene, S. (2002). Unconscious masked priming depends on temporal attention. Psychological Science, 13, 416-424.

NACCACHE, L., \& DEHAENE, S. (2001). Unconscious semantic priming extends to novel unseen stimuli. Cognition, 80, 215-229.

Neely, J. H. (1991). Semantic priming effects in visual word recognition: A selective review of current findings and theories. In D. Besner \& G. W. Humphreys (Eds.), Basic processes in reading: Visual word recognition (pp. 264-336). Hillsdale, NJ: Erlbaum.

Neumann, O., \& Klotz, W. (1994). Motor responses to nonreportable masked stimuli: Where is the limit of direct parameter specification? In C. Umiltà \& M. Moscovitch (Eds.), Attention and performance $X V$ : Conscious and nonconscious information processing (pp. 123150). Cambridge, MA: MIT Press.

Pansky, A., \& Algom, D. (2002). Comparative judgment of numerosity and numerical magnitude: Attention preempts automaticity. Journal of Experimental Psychology: Learning, Memory, \& Cognition, 28, 259-274.

PeCHER, D., Zeelenberg, R., \& RaAijmakers, J. G. W. (2002). Associative priming in a masked perceptual identification task: Evidence for automatic processes. Quarterly Journal of Experimental Psychology, 55A, 1157-1173. 
Perea, M., \& Rosa, E. (2002). Does the proportion of associatively related pairs modulate the associative priming effect at very brief stimulus-onset asynchronies? Acta Psychologica, 110, 103-124.

Poldrack, R. A., \& Gabrieli, J. D. E. (2001). Characterizing the neural mechanisms of skill learning and repetition priming: Evidence from mirror reading. Brain, 124, 67-82.

RATCLIF,, R., \& McKoon, G. (1988). A retrieval theory of priming in memory. Psychological Review, 95, 385-408.

RatCliff, R., \& McKoon, G. (1994). Retrieving information from memory: Spreading-activation theories versus compound-cue theories. Psychological Review, 101, 177-184.

RatclifF, R., \& MCKoON, G. (1997). A counter model for implicit priming in perceptual word identification. Psychological Review, 104, 319-343.

RATCLIFF, R., McKoon, G., \& Verwoerd, M. (1989). A bias interpretation of facilitation in perceptual identification. Journal of Experimental Psychology: Learning, Memory, \& Cognition, 15, 378-387.

Reynvoet, B., \& Brysbaert, M. (1999). Single-digit and two-digit Arabic numerals address the same semantic number line. Cognition, 72, 191-201.

Reynvoet, B., Caessens, B., \& Brysbaert, M. (2002). Automatic stimulus-response associations may be semantically mediated. Psychonomic Bulletin \& Review, 9, 107-112.

SudEVAN, P., \& TAYLOR, D. A. (1987). The cuing and priming of cog- nitive operations. Journal of Experimental Psychology: Human Perception \& Performance, 13, 89-103.

Tulving, E., \& THOMSON, D. (1973). Encoding specificity and retrieval processes in episodic memory. Psychological Review, 80, 352-373. ULRICH, R., \& MilleR, J. (1994). Effects of truncation on reaction time analysis. Journal of Experimental Psychology: General, 123, 34-80.

WhitTleseA, B. W. A., \& JACOBY, L. L. (1990). Interaction of prime repetition with visual degradation: Is priming a retrieval phenomenon? Journal of Memory \& Language, 29, 546-565.

\section{NOTES}

1. Overall, responses were faster for even targets than for odd targets in the parity task (Experiments 1-4; e.g., Hines, 1990) and for targets greater than 5 than for targets less than 5 in the magnitude task (Experiments 3-4; e.g., Koechlin et al., 1999). However, the left-right assignment of responses was the same for all subjects, so it is unclear whether these effects are due to faster responding with the right hand, or due to a more fundamental difference between these target types. For present purposes, it was not deemed necessary to tease these alternatives apart because the effects of prime validity that we report never interacted with target type.

2. Thanks to Rolf Verleger for providing the analyses that confirmed this bias pattern.

APPENDIX A

Experiments 1 and 2: ANOVA Results

\begin{tabular}{|c|c|c|c|c|c|c|c|c|}
\hline \multirow[b]{3}{*}{ Effect } & \multicolumn{4}{|c|}{ Reaction Time } & \multicolumn{4}{|c|}{ Percent Error } \\
\hline & \multicolumn{2}{|c|}{ Full Set } & \multicolumn{2}{|c|}{ Unaware } & \multicolumn{2}{|c|}{ Full Set } & \multicolumn{2}{|c|}{ Unaware } \\
\hline & $F(1,38)$ & $M S_{\mathrm{e}}$ & $F(1,23)$ & $M S_{\mathrm{e}}$ & $F(1,38)$ & $M S_{\mathrm{e}}$ & $F(1,23)$ & $M S_{\mathrm{e}}$ \\
\hline \multicolumn{9}{|c|}{ Experiment 1} \\
\hline PV & $4.04 *$ & 7,451 & 2.91 & 7,045 & 2.64 & 35.7 & 0.76 & 42.6 \\
\hline TP & $17.71 *$ & 468 & $9.51 *$ & 410 & 0.37 & 14.0 & 1.43 & 11.8 \\
\hline $\mathrm{PV} \times \mathrm{TP}$ & 0.07 & 468 & 0.28 & 410 & 0.00 & 14.0 & 1.48 & 11.8 \\
\hline Priming & $19.50^{*}$ & 395 & $12.23 *$ & 489 & $16.66^{*}$ & 17.0 & $10.48^{*}$ & 20.8 \\
\hline $\mathrm{PV} \times$ priming & $13.57^{*}$ & 395 & $6.34 *$ & 489 & $7.18 *$ & 17.0 & 1.27 & 20.8 \\
\hline $\mathrm{TP} \times$ priming & 0.35 & 269 & 0.48 & 366 & 0.93 & 12.6 & 4.05 & 12.7 \\
\hline $\mathrm{PV} \times$ priming $\times \mathrm{TP}$ & 0.60 & 269 & 0.23 & 366 & 1.91 & 12.6 & 0.21 & 12.7 \\
\hline \multicolumn{9}{|c|}{ Experiment 2} \\
\hline PV & 0.45 & 11,234 & 0.86 & 14,415 & 2.24 & 29.7 & $4.30^{*}$ & 29.3 \\
\hline $\mathrm{TP}$ & $16.08^{*}$ & 502 & $4.47 *$ & 626 & 0.00 & 5.5 & 0.86 & 5.2 \\
\hline $\mathrm{PV} \times \mathrm{TP}$ & 0.01 & 502 & 0.07 & 626 & 0.05 & 5.5 & 0.19 & 5.2 \\
\hline Priming & $43.01 *$ & 248 & $29.69^{*}$ & 288 & $34.16^{*}$ & 10.2 & $19.74 *$ & 13.2 \\
\hline $\mathrm{PV} \times$ priming & $13.73 *$ & 248 & $5.78^{*}$ & 288 & $10.35^{*}$ & 10.2 & $7.30^{*}$ & 13.2 \\
\hline $\mathrm{TP} \times$ priming & $4.14 *$ & 380 & 0.67 & 524 & 0.97 & 6.4 & 0.68 & 7.6 \\
\hline $\mathrm{PV} \times$ priming $\times \mathrm{TP}$ & 0.57 & 380 & 0.23 & 524 & 0.33 & 6.4 & 0.61 & 7.6 \\
\hline
\end{tabular}

Note-Full set, all subjects; unaware, unaware subjects only; PV, prime validity; TP, target parity. $\quad * p<.05$. 
APPENDIX B

Experiment 3: ANOVA Results

\begin{tabular}{|c|c|c|c|c|c|c|c|c|}
\hline \multirow[b]{3}{*}{ Effect } & \multicolumn{4}{|c|}{ Reaction Time } & \multicolumn{4}{|c|}{ Percent Error } \\
\hline & \multicolumn{2}{|c|}{ Full Set } & \multicolumn{2}{|c|}{ Unaware } & \multicolumn{2}{|c|}{ Full Set } & \multicolumn{2}{|c|}{ Unaware } \\
\hline & $F$ & $M S_{\mathrm{e}}$ & $F$ & $M S_{\mathrm{e}}$ & $F$ & $M S_{\mathrm{e}}$ & $F$ & $M S_{\mathrm{e}}$ \\
\hline \multicolumn{9}{|c|}{ Parity Task } \\
\hline PV & 0.03 & 15,845 & 0.00 & 16,407 & 0.02 & 14.6 & 0.02 & 13.2 \\
\hline $\mathrm{TP}$ & $37.33 *$ & 532 & $37.90 *$ & 505 & 0.49 & 6.8 & 1.57 & 6.0 \\
\hline $\mathrm{PV} \times \mathrm{TP}$ & 1.23 & 532 & 1.84 & 505 & 2.12 & 6.8 & 0.14 & 6.0 \\
\hline Priming & $31.24 *$ & 459 & $25.81 *$ & 515 & $24.16^{*}$ & 6.8 & $19.69^{*}$ & 7.2 \\
\hline $\mathrm{PV} \times$ priming & $12.79^{*}$ & 459 & $11.05^{*}$ & 515 & 2.35 & 6.8 & 2.16 & 7.2 \\
\hline $\mathrm{TP} \times$ priming & $5.68 *$ & 429 & $7.30 *$ & 434 & 0.24 & 5.8 & 0.04 & 5.4 \\
\hline $\mathrm{PV} \times$ priming $\times \mathrm{TP}$ & 0.19 & 429 & 0.60 & 434 & 0.36 & 5.8 & 0.04 & 5.4 \\
\hline \multicolumn{9}{|c|}{ Magnitude Task } \\
\hline PV & 0.41 & 12,769 & 0.01 & 15,084 & 3.48 & 18.7 & $4.77 *$ & 19.5 \\
\hline $\mathrm{TM}$ & $31.27 *$ & 505 & $24.92 *$ & 509 & 0.75 & 5.9 & 1.13 & 6.5 \\
\hline $\mathrm{PV} \times \mathrm{TM}$ & 0.34 & 505 & 0.72 & 509 & 0.62 & 5.9 & 1.30 & 6.5 \\
\hline Priming & $141.57 *$ & 343 & $96.73 *$ & 356 & $29.77 *$ & 9.9 & $18.71^{*}$ & 10.9 \\
\hline $\mathrm{PV} \times$ priming & $6.91 *$ & 343 & $4.68 *$ & 356 & $11.84 *$ & 9.9 & $14.65^{*}$ & 10.9 \\
\hline $\mathrm{TM} \times$ priming & 3.00 & 206 & 3.07 & 201 & 2.82 & 5.5 & 3.17 & 6.3 \\
\hline $\mathrm{PV} \times$ priming $\times \mathrm{TM}$ & 0.70 & 206 & 0.48 & 201 & 0.01 & 5.5 & 0.18 & 6.3 \\
\hline
\end{tabular}

Note-Full set, all subjects; unaware, unaware subjects only; PV, prime validity; TP, target parity; TM, target magnitude. Parity task $d f$ are 1 and 45 (full) and 1 and 38 (unaware). Magnitude task $d f$ are 1 and 99 (full) and 1 and 78 (unaware). $* p<$ .05 .

(Manuscript received January 2, 2004;

revision accepted for publication May 5, 2004.) 